\title{
Comparison of optical indicators for potato crop nitrogen status assessment including novel approaches based on leaf fluorescence and flavonoid content
}

\author{
F. Ben Abdallah, W. Philippe \& J. P. Goffart
}

To cite this article: F. Ben Abdallah, W. Philippe \& J. P. Goffart (2018) Comparison of optical indicators for potato crop nitrogen status assessment including novel approaches based on leaf fluorescence and flavonoid content, Journal of Plant Nutrition, 41:20, 2705-2728, DOI: 10.1080/01904167.2018.1510514

To link to this article: https://doi.org/10.1080/01904167.2018.1510514

巴nublished online: 31 Jan 2019.

Submit your article to this journal ¿

View Crossmark data $₫$ 


\title{
Comparison of optical indicators for potato crop nitrogen status assessment including novel approaches based on leaf fluorescence and flavonoid content
}

\author{
F. Ben Abdallah, W. Philippe, and J. P. Goffart \\ Department of Production and Sectors, Crops Production Systems Unit, Walloon Agricultural Research Centre \\ (CRA-W), Gembloux, Belgium
}

\begin{abstract}
Some phenolic compounds are proposed as good indicators of crop nitrogen status (CNS). This research compared the use of leaf flavonoid content (LFC) as a potential indicator for evaluating potato CNS with other recognized indicators linked to leaf chlorophyll content (LCC). Three-year trials were conducted in Belgium on two potato cultivars including increasing nitrogen rates. Optical sensors (Dualex, Multiplex, Hydro $\mathrm{N}$-tester, Cropscan) were used to evaluate LFC and/or LCC. Plant tissue samples were analyzed to calculate the biomass nitrogen concentration and the nitrogen nutrition index. The indicators were evaluated based on four criteria: the sensitivity, the earliness of the diagnosis, the accuracy, and the specificity. Apart from the low specificity to nitrogen, which can be improved by the use of a within-field reference plot, the LFC (combined with LCC or individually) matched the required criteria and could be suggested as a valuable indicator for assessing potato CNS.
\end{abstract}

\section{ARTICLE HISTORY}

Received 20 September 2017

Accepted 12 March 2018

\section{KEYWORDS}

leaf flavonoid content; leaf chlorophyll content; nitrogen; potato; optical sensors

\section{Introduction}

Nitrogen $(\mathrm{N})$ is an essential nutrient in plant growth, affecting both yield and quality. Potato crops have low $\mathrm{N}$ use efficiency because of the plant's poorly developed root system, which also increases the risk of $\mathrm{N}$ loss through leaching. To maintain yield and quality and to prevent environmental pollution, the crop's $\mathrm{N}$ use efficiency needs to be improved. This implies careful management of $\mathrm{N}$ fertilization by determining the optimum rates and dates of $\mathrm{N}$ fertilizer applications.

Relevant $\mathrm{N}$ strategies combine splitting the recommended $\mathrm{N}$ dose (estimated before planting) and the assessment during growth of the potato crop's N status (CNS) (Goffart et al. 2008).

Several in-season plant-based methods have been developed over the past few decades to assess potato CNS. Such methods can help in deciding about the need for supplementary $\mathrm{N}$ fertilizer application. The Nitrogen Nutrition Index (NNI) is a reference method which identifies situations of deficient and non-deficient N used to assess CNS. Establishing the NNI at field level, however, requires destructive and chemical analysis and is not appropriate for a quick assessment of CNS. The NNI can be used as a reference for calibrating other noninvasive methods for the quick and easy in-season monitoring of CNS (Goffart et al. 2008).

These methods imply the use of handheld sensors (Goffart et al. 2008) based on spectral characteristics of leaf transmittance (Vos and Bom 1993), reflectance (Gitelson and Merzlyak 
1998), and fluorescence (Ben Abdallah et al. 2016a) for the estimation of indicators closely related to the crops' $\mathrm{N}$ nutrition. These handheld sensors (chlorophyll-meters for transmittance, radiometers for reflectance and fluorimeters for fluorescence) commonly use the major symptom of $\mathrm{N}$ deficiency associated with a decrease of leaf chlorophyll content (LCC). Two major problems have been reported with the use of transmittance-based measurements by chlorophyll-meters (Cerovic et al. 2015). These are the nonlinear response of the sensor to optimal and supraoptimal $\mathrm{N}$ contents due to the physiological saturation of leaf chlorophyll response to $\mathrm{N}$ (Cerovic et al. 2012) and the influence of dry leaf mass per area (LMA), which reduces the accuracy of prediction of leaf $\mathrm{N}$ concentration expressed in dry-weight by a surface-based measurement (Peng et al. 1993). The potential advantages of reflectance-based measurements alone are inadequate, in view of delayed sensitivity, lack of specificity to $\mathrm{N}$ stresses, and potentially erroneous information from nonvegetated soil (Tremblay et al. 2012).

Regarding these problems, phenolic compounds have been proposed as a potential CNS indicator. Flavonoids are a class of phenolic compounds related to plant $\mathrm{N}$ content. Nitrogen deficiency induces an increase in leaf flavonoid content (LFC) (Mittelstraß et al., 2006 Stewart et al. 2001). Sensors using chlorophyll fluorescence have been developed to assess LFC, such as the Dualex (Goulas et al. 2004; Cerovic et al. 2005; Cartelat et al. 2005; Tremblay et al. 2007) and Multiplex (Ben Ghozlen et al. 2010; Zhang et al. 2012) fluorimeters. Flavonoids could be used as a surrogate of LMA (Cerovic et al. 2012), since there is a very good correlation between the two (both are controlled by leaf irradiance) (Meyer et al. 2006).

In addition to the single-indicator approach (LCC or more recently LFC), a double-indicator approach that combines the detection of LCC and LFC as a ratio of chlorophyll to flavonoids has been suggested as a promising approach for assessing CNS (Cartelat et al. 2005; Tremblay et al. 2007, 2009; Agati et al. 2013). Research by Cartelat et al. (2005) on winter wheat concluded that the combined ratio would alleviate, at least partially, the problem of chlorophyll and flavonoids gradients along leaves. This ratio was proposed as a solution for preventing the influence of LMA, because the unit of expression becomes irrelevant (Cerovic et al. 2012). It also improves discrimination between levels of CNS because of the opposite effect of $\mathrm{N}$ nutrition on chlorophyll and flavonoids (Cartelat et al. 2005; Tremblay et al. 2007), with the result that LCC decreases with decreasing leaf $\mathrm{N}$ content, whereas LFC increases with increasing leaf $\mathrm{N}$ content.

The objective of the current study was to evaluate the potential of LFC, alone or combined with LCC, in the assessment of potato CNS. Based on a comparative study of indices provided by various optical sensors, four criteria were considered for assessing the potential of LFC: (1) the sensitivity of the readings; (2) the earliness of the diagnosis of CNS; (3) the accuracy (precision and repeatability) of the readings; and (4) the specificity of the indices. This paper describes the results of a 3-year trial $(2012,2013$, and 2014) including two potato cultivars in Belgian conditions.

\section{Materials and methods}

\subsection{Field trials and experimental design}

A first type of experiment was conducted at the experimental site of the Walloon Agriculture Research Center in Gembloux, Belgium in 2012 and 2013. The experiments included two potato [Solanum tuberosum (L.)] cultivars, Charlotte and Bintje (early and mid-early cultivars, respectively), and six increasing $\mathrm{N}$ fertilizer rates for each cultivar. The trial cropping characteristics are given in Table 1. The experimental design was a split plot with four replications. The cultivar was the main-plot factor and $\mathrm{N}$ treatment was the subplot factor. Each subplot was eight rows wide and divided into two parts. The first part was used for the optical readings and plant sampling during the season; the second part was used for the assessment of final yield. Only the four central rows of each plot were considered for readings and sampling, avoiding the border rows. 
Table 1. Crop and soil characteristics of the 3-year trials conducted at the Walloon Agriculture Research Center in Gembloux, Belgium.

\begin{tabular}{|c|c|c|c|c|c|c|}
\hline \multirow{4}{*}{$\begin{array}{l}\text { Year } \\
\text { Type of soil } \\
\text { Previous crop } \\
\text { Cultivar }\end{array}$} & \multicolumn{2}{|c|}{2012} & \multicolumn{2}{|c|}{2013} & \multicolumn{2}{|c|}{2014} \\
\hline & \multicolumn{2}{|c|}{ Clay loam } & \multicolumn{2}{|c|}{ Clay loam } & \multicolumn{2}{|c|}{ Clay loam } \\
\hline & \multicolumn{2}{|c|}{ Cereal crop } & \multicolumn{2}{|c|}{ Cereal crop } & \multicolumn{2}{|c|}{ Cereal crop } \\
\hline & Bintje & Charlotte & Bintje & Charlotte & Bintje & Charlotte \\
\hline Organic matter (\%) & 2.2 & 2.2 & 1.3 & 1.3 & 2.1 & 2.1 \\
\hline Soil mineral N (kg/ha) $(0-60) \mathrm{cm})$ & 46 & 46 & 36 & 36 & 72 & 72 \\
\hline Planting density $\left(m^{*} m\right)$ & \multicolumn{2}{|c|}{$0.75^{*} 0.35$} & \multicolumn{2}{|c|}{$0.75 * 0.35$} & \multicolumn{2}{|c|}{$0.75^{*} 0.35$} \\
\hline Applied N (kg.ha $\left.{ }^{-1}\right)$ & \multicolumn{2}{|c|}{$0-50-100-150-200-250$} & \multicolumn{2}{|c|}{$0-50-100-150-200-250$} & \multicolumn{2}{|c|}{$0-100-200-250$} \\
\hline Planting date & $13 / 5$ & $13 / 5$ & $25 / 4$ & $25 / 4$ & $15 / 4$ & $15 / 4$ \\
\hline Emergence date & $2 / 6$ & $1 / 6$ & $7 / 6$ & $5 / 6$ & $21 / 5$ & $18 / 5$ \\
\hline Harvest date & $01 / 10$ & $10 / 9$ & $23 / 9$ & $3 / 9$ & $23 / 9$ & $02 / 9$ \\
\hline
\end{tabular}

Table 2. Measurement dates for optical sensors used in this study.

Optical measurement dates ${ }^{\mathrm{a}}$

\begin{tabular}{|c|c|c|c|c|c|}
\hline \multicolumn{2}{|c|}{2012} & \multicolumn{2}{|c|}{2013} & \multicolumn{2}{|c|}{2014} \\
\hline Charlotte & Bintje & Charlotte & Bintje & Charlotte & Bintje \\
\hline- & - & $11 / 06(7)$ & $14 / 06(8)$ & $11 / 06(25)$ & $11 / 06(22)$ \\
\hline 19/06 (19) & 20/06 (19) & $17 / 06(13)$ & $19 / 06(13)$ & $16 / 06(30)$ & $18 / 06$ (29) \\
\hline $25 / 06(25)$ & $26 / 06(25)$ & $24 / 06(20)$ & $26 / 06(20)$ & $26 / 06(40)$ & $26 / 06$ (37) \\
\hline $02 / 07$ (32) & $03 / 07$ (32) & $01 / 07$ (27) & 04/07 (28) & $30 / 06(44)$ & 03/07 (44) \\
\hline 09/07 (39) & 10/07 (39) & 08/07 (34) & $10 / 07(34)$ & $17 / 07$ (61) & $17 / 07$ (58) \\
\hline $16 / 07$ (46) & $17 / 07$ (46) & $15 / 07(41)$ & $18 / 07(42)$ & $24 / 07$ (68) & $24 / 07$ (65) \\
\hline $23 / 07$ (53) & $24 / 07$ (53) & $22 / 07(48)$ & $24 / 07$ (48) & 29/07 (73) & $31 / 07(72)$ \\
\hline
\end{tabular}

${ }^{a}$ Measurements provided with the Hydro N-Tester (HNT, Yara, Oslo, Norway), Dualex, Multiplex (Force-A, Orsay, France), and for 2012 and 2013 trials with Cropscan (Cropscan Inc, Rochester, USA), Numbers in parentheses indicate the day after emergence (DAE) of the crop.

A second type of experiment was also conducted in 2014 in Gembloux to confirm the results of the first 2 years' preliminary trials. The trial included the same cultivars and four increasing $\mathrm{N}$ rates with the same $\mathrm{N}$ fertilizer (Table 1).

Ammonium nitrate fertilizer (ANF, solid granules, $27 \% \mathrm{~N}+4 \% \mathrm{MgO}$ ) was broadcast and incorporated at planting. Phosphorus (P) and potassium (K) fertilizers were applied before planting at rates of $70-80 \mathrm{~kg} \mathrm{P}_{2} \mathrm{O}_{5} \mathrm{ha}^{-1}$ and $250-300 \mathrm{~kg} \mathrm{~K}_{2} \mathrm{O} \mathrm{ha}^{-1}$. Trials were rain fed.

\subsection{Soil and weather data acquisition}

The soil mineral nitrogen content was assessed using the method developed by Guiot et al. (1993). The trials were rain fed and the soil water content was monitored during the growing season using soil tensiometer probes (Watermark probes, Irrometer Company, California) to detect drought stress periods. The mean water tension values (expressed in $\mathrm{kPa}$ ) of six probes placed at a depth of $25 \mathrm{~cm}$ from the top of the ridge were recorded. The probes were distributed uniformly across the experimental field. Daily precipitation $\left(\mathrm{l} \mathrm{m}^{-2}\right)$ and air temperature $\left({ }^{\circ} \mathrm{C}\right)$ were recorded at an official weather station (Belgian Royal Meteorological Institute, IRM) located near the experimental field. These data related to crop conditions are relevant to demonstrate that the performances of the optical indicators were tested under different cropping season's conditions.

\subsection{Optical data collection and analysis}

Optical readings were carried out weekly during the crop growth period from mid-June to the end of July for the 3 years (Table 2). The measurements were collected for each year at the same date or at the closest date for both cultivars. 
All the readings were made on plants with a uniform appearance within each plot and at the same plant development stages with the various tested sensors, but not necessarily on the same leaves or plants. Similarly, readings were not taken on the same leaves or plants on different dates.

The optical sensors tested in this study were the chlorophyll-meter Hydro N-Tester (Yara, Oslo, Norway), the fluorimeters Dualex and Multiplex 375 (Force-A, Orsay, France), and for 2012 and 2013 trials the radiometer Cropscan (Cropscan Inc, Rochester, USA). The collected raw signals and calculated indices are summarized in Table 3.

The Hydro N-Tester chlorophyll-meter and the Dualex fluorimeter are handheld leaf clip sensors (corresponding to leaf areas of $2-3 \mathrm{~mm}^{2}$ and $19-20 \mathrm{~mm}^{2}$ per reading, respectively). Single readings were taken on the distal leaflet of the first fully developed leaf from the top of the canopy (corresponding to the fourth or fifth leaf from the apex of a main stem), avoiding midribs. The measurements focused on the upper face of the leaf. On each date, 30 individual readings were collected for each plot and averaged across the replications of the same $\mathrm{N}$ treatment.

Both sensors provided indices related to the LCC expressed as HNT index (Hydro N-Tester) and as CHL index (Dualex) (Table 3). The measurements are based on the transmittance of two wavelengths, red (R), and near-infrared (NIR). The R wavelength is absorbed by chlorophyll, whereas for the NIR wavelength no absorption occurs for chlorophyll; absorption is then related to leaf water content and leaf cell wall structure. The $\mathrm{R}$ and NIR wavelengths provided by the Hydro N-Tester are 650 and $940 \mathrm{~nm}$, respectively. However, the R and NIR wavelengths provided by the Dualex are 710 and $850 \mathrm{~nm}$, respectively. The $\mathrm{R}$ wavelength provided by the Hydro $\mathrm{N}$-Tester is characterized by a large chlorophyll absorption coefficient, whereas the $\mathrm{R}$ wavelength provided by the Dualex is characterized by a small chlorophyll absorption coefficient (Cerovic et al. 2012). Using an $\mathrm{R}$ wavelength with a large chlorophyll absorption coefficient increases the accuracy at low LCC and reduces the accuracy at high LCC. An R wavelength with a small chlorophyll absorption coefficient reduces the accuracy over the whole range of LCC but lessens the problem of saturation in the high chlorophyll range (Cerovic et al. 2012).

The Dualex sensor provides a second index, the FLV index (Table 3), which enables the estimation of LFC using the fluorescence emitted by chlorophyll. This fluorescence is induced by two excitation wavelengths: one in the UV $(375 \mathrm{~nm})$ wavelength and the other one in the R $(650 \mathrm{~nm})$ wavelength. The absorbance of leaf flavonoids is then determined by measuring the fluorescence excitation ratio FRF-UV/FRF-R, where FRF-UV is the far-red fluorescence detected following UV excitation and FRF- $\mathrm{R}$ is the far-red fluorescence detected following $\mathrm{R}$ excitation (Goulas et al. 2004). This approach is based on the UV screening properties of flavonoids (Bilger et al. 1997). The UV wavelength is absorbed by flavonoids located mainly in the leaf epidermis, therefore reducing the amount of light available for chlorophyll fluorescence. The reference wavelength in $\mathrm{R}$ goes through the epidermis without being absorbed by flavonoids and reaches the leaf mesophyll, where it is absorbed by chlorophyll. The third index provided by the Dualex device is the NBI index, calculated as the CHL/FLV ratio.

The Multiplex 375 fluorimeter is a handheld multiparametric fluorescence sensor for measurements on leaves using a near-remote sensing approach. The sensor generates four excitations in the UV $(375 \mathrm{~nm})$, blue $(B, 470 \mathrm{~nm})$, green $(\mathrm{G}, 515 \mathrm{~nm})$, and $\mathrm{R}(635 \mathrm{~nm})$ wavelengths and detects yellow (YF, $590 \mathrm{~nm}$ ), red (RF, $685 \mathrm{~nm}$ ), and far-red (FRF, $735 \mathrm{~nm}$ ) fluorescence (Ben Ghozlen et al. 2010). Measurement distance to leaves is $10 \mathrm{~cm}$ from active light sources and the impacted leaf area is $50 \mathrm{~cm}^{2}$. The sensor was held facing downward, perpendicular to the leaf surface. The Multiplex readings were taken on sets of fully developed leaves from the top of the canopy, as with the Dualex and Hydro $\mathrm{N}$-tester readings. On each date, 30 individual measurements were taken in each plot and averaged across the replications of the same $\mathrm{N}$ treatment.

Several fluorescence ratios from the various wavelengths were computed directly using the Multiplex device to supply information related to leaf chlorophyll and flavonoid contents (Table 3). The Multiplex LCC was estimated using the SFR-R index, defined as the simple 
Table 3. Description of the $\mathrm{N}$-indices provided by the different optical sensors used in this study.

\begin{tabular}{|c|c|c|c|c|}
\hline Optical sensors $^{\mathrm{a}}$ & Index & Description & Excitation & Formula \\
\hline \multirow[t]{7}{*}{ Dualex } & FRF-R & Far red fluorescence (FRF) & Red (R) & - \\
\hline & FRF-UV & Far red fluorescence (FRF) & Ultraviolet (UV) & - \\
\hline & $\mathrm{T}_{710}$ & Transmittance & $\mathrm{R}$ & - \\
\hline & $\mathrm{T}_{850}$ & Transmittance & Infra-red (IR) & - \\
\hline & $\mathrm{CHL}$ & Transmittance (chlorophyll) & $\mathrm{R}$ and $\mathrm{IR}$ & $\left(1 / T_{850}\right)-\left(1 / T_{710}\right)$ \\
\hline & FLV & Fluorescence (flavonoids) & $\mathrm{R}$ and UV & Log(FRF-R/FRF-UV) \\
\hline & $\mathrm{NBI}$ & Nitrogen balance index & - & $\mathrm{CHL} / \mathrm{FLV}$ \\
\hline \multirow[t]{10}{*}{ Multiplex } & FRF-G & Far red fluorescence (FRF) & Green (G) & - \\
\hline & FRF-R & Far red fluorescence (FRF) & $\mathrm{R}$ & - \\
\hline & FRF-UV & Far red fluorescence (FRF) & UV & - \\
\hline & $R F-G$ & Red fluorescence (RF) & $\mathrm{G}$ & - \\
\hline & RF-R & Red fluorescence (RF) & $\mathrm{R}$ & - \\
\hline & SFR-G & $\begin{array}{l}\text { Simple fluorescence ratio } \\
\text { (chlorophyll) }\end{array}$ & G & FRF-G/RF-G \\
\hline & SFR-R & $\begin{array}{l}\text { Simple fluorescence ratio } \\
\text { (chlorophyll) }\end{array}$ & $\mathrm{R}$ & FRF-R/RF-R \\
\hline & FLAV & Fluorescence (flavonoids) & $\mathrm{R}$ and UV & Log(FRF-R/FRF-UV) \\
\hline & NBI-G & Nitrogen balance index & & SFR-G/FLAV \\
\hline & NBI-R & Nitrogen balance index & & SFR-R/FLAV \\
\hline Hydro $\mathrm{N}$ tester & HNT & Transmittance (chlorophyll) & $\mathrm{R}$ and $\mathrm{IR}$ & $\left(T_{R}\right)-\left(T_{I R}\right)$ \\
\hline $\begin{array}{l}\text { Hydro } \mathrm{N} \text { tester } \\
\text { and Dualex }\end{array}$ & HNT/FLV & $\begin{array}{l}\text { Combined ratio of chlorophyll } \\
\text { and flavonoid indicators }\end{array}$ & & HNT/FLV \\
\hline $\begin{array}{l}\text { Hydro } \mathrm{N} \text { tester } \\
\text { and Multiplex }\end{array}$ & HNT/FLAV & $\begin{array}{l}\text { Combined ratio of chlorophyll } \\
\text { and flavonoid indicators }\end{array}$ & & HNT/FLAV \\
\hline \multirow[t]{24}{*}{ Cropscan } & 460 & Reflectance (chlorophyll) & No excitation & $\left(\mathrm{RE}_{460} / \mathrm{I}_{460}\right) \times 100$ \\
\hline & 510 & $\begin{array}{l}\text { Ix: Incident light of } \\
\text { different } \times \text { wavelengths }\end{array}$ & $\begin{array}{l}\text { Source (use the } \\
\text { solar light) }\end{array}$ & $\left(\mathrm{RE}_{510} / \mathrm{I}_{510}\right) \times 100$ \\
\hline & 560 & & & $\left(\mathrm{RE}_{560} / \mathrm{I}_{560}\right) \times 100$ \\
\hline & 610 & $\begin{array}{l}\text { RE }: \text { Reflected light of } \\
\text { different } \times \text { wavelengths }\end{array}$ & & $\left(\mathrm{RE}_{610} / \mathrm{I}_{610}\right) \times 100$ \\
\hline & 660 & & & $\left(\mathrm{RE}_{660} / \mathrm{I}_{660}\right) \times 100$ \\
\hline & 710 & & & $\left(\mathrm{RE}_{710} / \mathrm{I}_{710}\right) \times 100$ \\
\hline & 760 & & & $\left(\mathrm{RE}_{760} / \mathrm{I}_{760}\right) \times 100$ \\
\hline & 810 & & & $\left(\mathrm{RE}_{810} / \mathrm{I}_{810}\right) \times 100$ \\
\hline & G & Reflectance in green & - & $\begin{array}{l}{\left[\left(\left(\mathrm{RE}_{510} / \mathrm{I}_{510}\right) \times 100\right)+\left(\left(\mathrm{RE}_{560} /\right.\right.\right.} \\
\left.\left.\left.\mathrm{I}_{560}\right) \times 100\right)\right] / 2\end{array}$ \\
\hline & $\mathrm{R}$ & Reflectance in red & - & $\begin{array}{l}{\left[\left(\left(\mathrm{RE}_{610} / \mathrm{I}_{610}\right) \times 100\right)+\left(\left(\mathrm{RE}_{660} /\right.\right.\right.} \\
\left.\left.\left.\quad \mathrm{I}_{660}\right) \times 100\right)\right] / 2\end{array}$ \\
\hline & NIR & Reflectance in near-infra-red & - & $\begin{array}{l}{\left[\left(\left(\mathrm{RE}_{760} / \mathrm{I}_{760}\right) \times 100\right)+\left(\left(\mathrm{RE}_{810} /\right.\right.\right.} \\
\left.\left.\left.\quad \mathrm{I}_{810}\right) \times 100\right)\right] / 2\end{array}$ \\
\hline & NormG & Normalized indices & & $\mathrm{G} /(\mathrm{NIR}+\mathrm{R}+\mathrm{G})$ \\
\hline & NormR & & & $\mathrm{R} /(\mathrm{NIR}+\mathrm{R}+\mathrm{G})$ \\
\hline & NormNIR & & & $\mathrm{NIR} /(\mathrm{NIR}+\mathrm{R}+\mathrm{G})$ \\
\hline & DVI & Vegetation indices & & NIR-R \\
\hline & GDVI & & & NIR-G \\
\hline & $\mathrm{RVI}$ & & & $\mathrm{NIR} / \mathrm{R}$ \\
\hline & GRVI & & & $\mathrm{NIR} / \mathrm{G}$ \\
\hline & NDVI & & & $(N I R-R) /(N I R+R)$ \\
\hline & GNDVI & & & $(\mathrm{NIR}-\mathrm{G}) /(\mathrm{NIR}+\mathrm{G})$ \\
\hline & SAVI & & & $((N I R-R) /(N I R+R+0.5)) \times 1.5$ \\
\hline & GSAVI & & & $((\mathrm{NIR}-\mathrm{G}) /(\mathrm{NIR}+\mathrm{G}+0.5)) \times 1.5$ \\
\hline & OSAVI & & & $(\mathrm{NIR}-\mathrm{R}) /(\mathrm{NIR}+\mathrm{R}+0.16)$ \\
\hline & GOSAVI & & & $(\mathrm{NIR}-\mathrm{G}) /(\mathrm{NIR}+\mathrm{G}+0.16)$ \\
\hline
\end{tabular}

aHydro N-Tester (HNT, Yara, Oslo, Norway), Cropscan (Cropscan Inc, Rochester, USA), Dualex and Multiplex (Force-A, Orsay, France).

fluorescence emission ratio between FRF and RF induced under $\mathrm{R}$ excitation. This parameter is based on increasing chlorophyll fluorescence re-absorption at its shorter wavelength peak when chlorophyll content increases (Buschmann 2007). The Multiplex LFC was estimated using the FLAV index, which is based on the same principle of fluorescence excitation ratio as the Dualex FLV index. However, a difference exists between the two devices: in the Dualex, the use of an electronic feedback loop avoids the variable chlorophyll fluorescence, while in the Multiplex there 
is no feedback loop. The feedback loop minimizes the difference between variable chlorophyll fluorescence induced under R and UV excitation (Goulas et al. 2004). In the Multiplex, thanks to the rapid alternating light sources between the two excitations, the fluorescence induced under $\mathrm{R}$ and UV excitation remains constant.

The NBI-G and NBI-R indices were provided by the Multiplex and related to both leaf chlorophyll and flavonoids content.

The HNT/FLV and HNT/FLAV indices (Table 3) were also calculated as combined ratios between the chlorophyll index provided using the Hydro N-Tester device and the flavonoid index provided by the Dualex or Multiplex sensors, respectively.

The Cropscan radiometer is a passive near-remote sensing device used for measuring crop light reflectance. The radiometer is extended on a boom at a height of $2 \mathrm{~m}$ above the ground $(\sim 1.5 \mathrm{~m}$ above the top of the canopy), providing a circular measurement area of $1 \mathrm{~m}$ in diameter at ground level.

The Cropscan readings were taken between noon and $2.00 \mathrm{pm}$ (GMT). The radiometer faced downward, perpendicular to the crop surface (nadir view). On each date, five measurements were made within each plot and averaged across the replications.

The sensor allowed eight wavebands of $15 \mathrm{~nm}$ wide to be used, with central values from 460 to $810 \mathrm{~nm}$ at $50 \mathrm{~nm}$ intervals. Total solar light irradiance and individual wavelength radiance were stored for each waveband, allowing the calculation of canopy reflectance as the ratio between radiance and irradiance. Reflectance at selected wavelengths is related to LCC. Leaves with the lowest chlorophyll contents have higher reflectance in the visible wavelengths and lower reflectance in the NIR wavelengths than leaves with higher chlorophyll levels (Daughtry et al. 2000).

The G, R, and NIR indices of the Cropscan (Table 3) were computed as canopy reflectance in the $G$ (mean reflectance of the 510 and $560 \mathrm{~nm}$ bands), $R$ (mean reflectance of the 610 and $660 \mathrm{~nm}$ bands), and NIR wavebands (mean reflectance of the 760 and $810 \mathrm{~nm}$ bands), respectively (Goffart et al. 2010). Spectral vegetation indices (VIs) were also computed by combining the low reflectance in the visible wavelengths with the high reflectance of the NIR wavelengths to minimize the extraneous factors (Daughtry et al. 2000).

\subsection{Plant sample collection and analysis}

Plant samples were collected in 2012, 2013, and 2014 (Table 4). The plant samplings were performed at the same date or close to the date of the optical measurements to compare the provided indices with the reference analytical method. Within each plot, eight whole plants were collected and taken to the laboratory. The plants were washed, air-dried, and weighed to determine the fresh weight of the shoots (leaves + stems), roots and tubers. Subsamples of each plant part were then dried at $80^{\circ} \mathrm{C}$ up to constant dry weight. The dry matter (DM) content of each sample was then calculated.

From the various plant parts (leaves + stems, tubers and roots), finely crushed samples with a Cyclotec 1093 sample mill (FOSS Tecator) were subjected to analytical measurements of total $\mathrm{N}$

Table 4. Plant sampling dates in 2012, 2013 and 2014 trials.

Sampling dates

\begin{tabular}{|c|c|c|c|c|c|}
\hline \multicolumn{2}{|c|}{2012} & \multicolumn{2}{|c|}{2013} & \multicolumn{2}{|c|}{2014} \\
\hline Charlotte & Bintje & Charlotte & Bintje & Charlotte & Bintje \\
\hline $27 / 06(27)$ & $27 / 06(26)$ & $17 / 06(13)$ & $19 / 06$ (13) & $16 / 06(30)$ & $18 / 06(29)$ \\
\hline $02 / 07(32)$ & $04 / 07$ (33) & $24 / 06(20)$ & $26 / 06(20)$ & $30 / 06(40)$ & $03 / 07(44)$ \\
\hline 09/07 (39) & $11 / 07(40)$ & $01 / 07$ (27) & $11 / 07$ (35) & $28 / 07(72)$ & $30 / 07(71)$ \\
\hline $16 / 07$ (46) & $25 / 07(54)$ & $15 / 07(41)$ & 23/07 (47) & - & - \\
\hline
\end{tabular}

Numbers in brackets indicate the day after emergence (DAE) of the crop. 
concentration conducted with NIR spectroscopy using a FOSS-NIR Systems 6500 scanning instrument (NIR-Systems, Silver Springs, MD) and calibrated using the Dumas Combustion method (LECO, St Joseph MI, USA) and the statistical method developed by Shenk and Westerhaus (1993). The NNI, defined as the ratio between the measured $\mathrm{N}$ concentration in shoots and tubers and the predicted critical $\mathrm{N}$ concentration $(\mathrm{Nc})$, was calculated according to the $\mathrm{Nc}$ dilution curve $\left(\mathrm{Nc}(\%)=5.37 \mathrm{~W}^{-0.45}, \mathrm{w}\right.$ is the shoot and tuber biomass expressed in $\mathrm{t} \mathrm{DM} \mathrm{ha}{ }^{-1}$ ) developed for the Bintje potato cultivar under Belgian conditions (Ben Abdallah et al. 2016b). In the absence of a reference Nc curve for Charlotte, the NNI for this cultivar was calculated in this study using the same equation as for Bintje. The NNI was measured for each sampling date, and then an average was calculated across the period between 20 and 55 DAE. The NNIs for Bintje were compared to a reference value of 1.16 . This reference of 1.16 is considered as the threshold value, to be achieved during the optimal period for CNS assessment; below this value, the CNS is considered as deficient with respect to maximum potential yields (Ben Abdallah et al. 2016b). Since differences in the Nc curve could exist between cultivars with different earliness (Ben Abdallah et al. 2016b), the obtained NNI for Charlotte was not used in this study to define the optimal $\mathrm{N}$ status (considering the reference value of 1.16), but used in order to demonstrate that the applied $\mathrm{N}$ fertilizer rate leads to different $\mathrm{N}$ status.

\subsection{Yield measurements}

Harvesting was done on the two central rows $(8 \mathrm{~m}$ long for 2012 and $6 \mathrm{~m}$ long for 2013 and 2014) for each plot. The tubers harvested were used to measure yield, DM content (expressed in $\%$ ) using the tuber underwater weigher (Robbe potato underwater weigher 9306, Belgium), and nitrate content using a hand-held electronic test meter (Nitrachek 404, KPG Products Ltd, UK).

\subsection{Assessment of the required criteria for the different studied indices}

To fully evaluate the usefulness of the optical indices from the readings for predicting the CNS, it was necessary to assess the sensitivity of the indices, their earliness for $\mathrm{N}$ diagnosis, their accuracy and their specificity. The sensitivity of an index indicates if it reacts to a change in the $\mathrm{N}$ treatment level. The earliness of the response suggests that the index should give an early detection of $\mathrm{N}$ deficiency, long before visual symptoms of chlorosis appear in the foliage. The accuracy of an index means that the readings related to the $\mathrm{N}$ status are near to the true value (precision) and repeatable (repeatability). Specificity to $\mathrm{N}$ means that the measurement should ideally be exclusively related to nitrogen status without interference from other external factors. These criteria are expected to adequately assess the CNS (Goffart et al. 2008).

\subsection{Data analysis}

The statistical analysis was performed with the SAS software package (SAS 9.4, SAS Inc., Cary NC). The studied indices were subjected to analysis of variance (ANOVA, proc glm) to study the sensitivity and earliness of the diagnosis on the basis of the $\mathrm{N}$ effect. The indices' responses to increasing $\mathrm{N}$ rates were studied across the sampling period including the 2 trial years $(2012$ and 2013) and both cultivars as a whole. For this analysis, the first measurement dates for 2013 for both cultivars were excluded, since no measurements were performed for the analogous period in 2012. The obtained indices, evaluated for each sampling date and for each cultivar, were then subjected to ANOVA (all the measurements were included). To confirm the results of the 2 trial years, the responses of the retained LFC indicators (individually and combined to LCC) to increasing $\mathrm{N}$ rates were also studied for the 2014 trial. 
As a complement, a ratio of sensitivity (RS) for each index was calculated to evaluate the ability of the index to assess highly contrasting $\mathrm{N}$ status. This method is similar to that proposed by Zhang et al. (2012). The RS was calculated between the value of the higher $\mathrm{N}$ treatment $(250 \mathrm{~N})$ divided by the value of the lowest $\mathrm{N}$ treatment $(0 \mathrm{~N})$ for each index. If the index value corresponding to the $0 \mathrm{~N}$ treatment was higher than the index value corresponding to the $250 \mathrm{~N}$ treatment, the reciprocal calculation of the ratio was made. These ratios were calculated for each index in the two trial years (2012 and 2013) including the cultivars and the measurements dates as a whole. The RS was also calculated for 2014 trial including the cultivars and the measurements dates as a whole.

The relationship between the optical indices and $\mathrm{N}$ concentration in shoots or in the whole plant biomass were investigated using the Pearson correlation coefficients (SAS) to assess the precision of the indices for the 2012 and 2013 trials.

The repeatability in this study was evaluated by the coefficient of variation of the indices (\%), calculated as the ratio between the standard deviation and the mean of the indices measured between the four replications by date (for both the 2012 and the 2013 trials) and combining the six levels of $\mathrm{N}$ rates.

The effects of different factors, such as the N, the cultivar, the year, the DAE and their interaction, were investigated to assess the specificity of the studied indices (absolute and relative indices). Unless specified otherwise, the provided optical indices were studied on the basis of absolute mean, absolute indices, obtained from the replicated plots average for the same $\mathrm{N}$ treatment. The relative indices were calculated using a within-trial reference plot: the well-fertilized reference plot (ratio of the absolute index for a given $\mathrm{N}$ treatment to the absolute index for the $250 \mathrm{~N}$ treatment) or the control reference plot (ratio of the absolute index for a given $\mathrm{N}$ treatment to the absolute index for the $0 \mathrm{~N}$ treatment). Specificity was investigated in the 3 trial years, including only measurements performed in analogous periods for 2012, 2013, and 2014. The absolute indices were compared to the relative indices on the basis of the ANOVA $p$ values and the associated $F$ ratio (Fisher-Snedecor ratio). For factors with significant $p$ values, the $F$ values of the index obtained for the different factors were compared in order to weight the effect of each factor. This method is similar to that proposed by Froidmont et al. (2013): a large $F$ ratio signifies a small probability that the null hypothesis is true. Therefore, the higher the $F$ ratio, the lower the probability.

\section{Results and discussion}

\subsection{Local soil and weather conditions}

The 2012 trial was characterized by relatively high precipitations in April, June, and July and low precipitation in May, August, and September (Figure 1a). The average precipitation recorded from April to September 2012 was $382.0 \mathrm{~mm}$ versus a normal average of $414.9 \mathrm{~mm}$. Except for the month of May, the 2013 trial experienced low precipitation (Figure 1a), with an average of $335.6 \mathrm{~mm}$ from April to September. Unusual rainy days were recorded in July and August for the 2014 trial (an average of $496.7 \mathrm{~mm}$ from April to September) (Figure 1a). The average air temperature recorded for the 3 years' growing seasons was slightly higher than the normal, particularly for 2014, when high temperatures were observed in April, July, and September (Figure 1a). The average air temperature recorded from April to September was $86.4^{\circ} \mathrm{C}$ in 2012, $85.4^{\circ} \mathrm{C}$ in 2013 and $90.4^{\circ} \mathrm{C}$ in 2014 versus a normal average temperature of $84.6^{\circ} \mathrm{C}$.

From the end of June to the end of July, corresponding to the main period of measurements with the different optical tools and of plant sampling, the soil water tension for 2012 (Figure 1b) ranged between 30 and $100 \mathrm{kPa}$, indicating sufficient water availability (linked to the high precipitation observed in Figure 1a) to cover crop water needs. For the 2013 trial, the soil water 


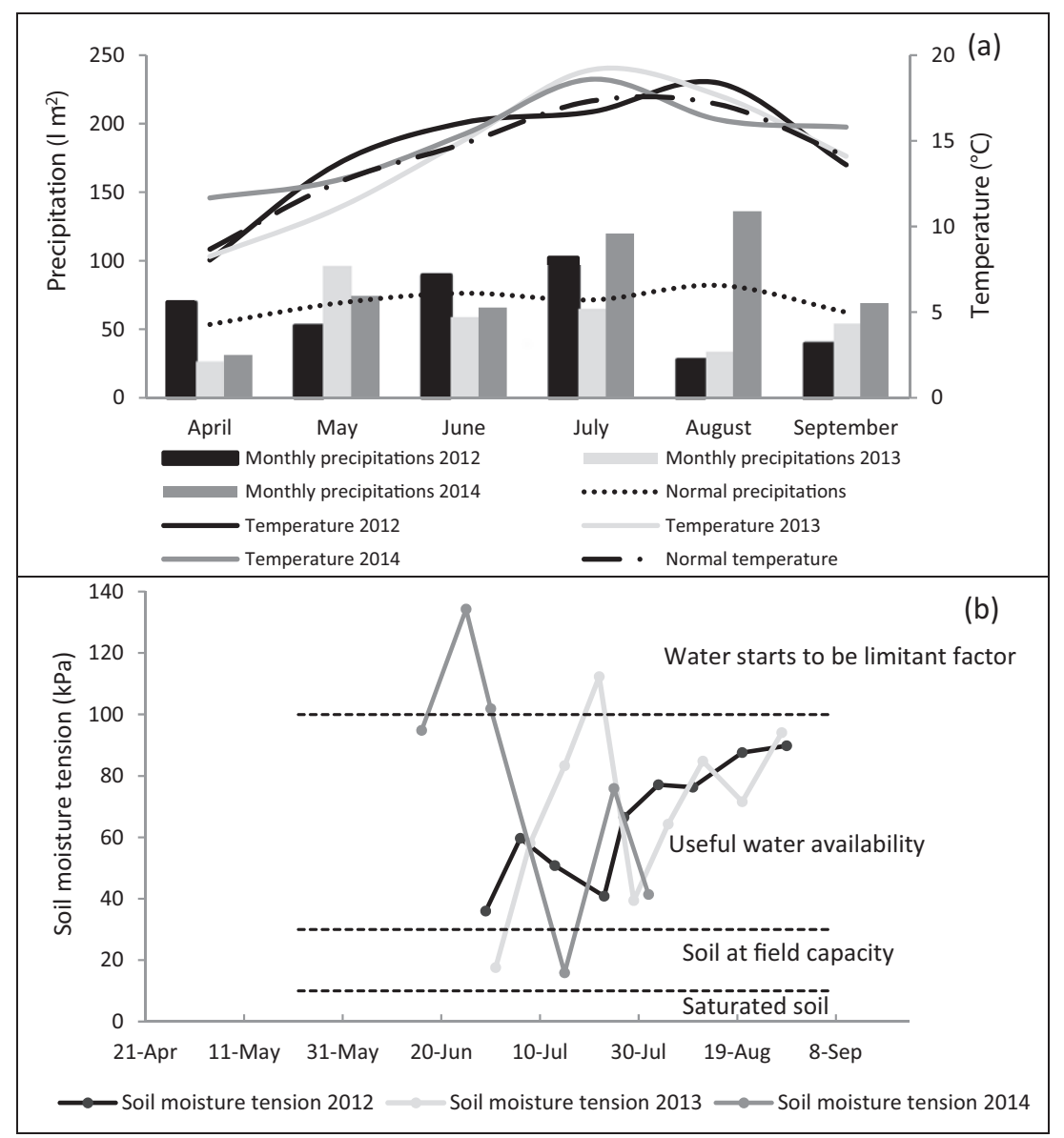

Figure 1. (a) Total monthly rainfall $\left(\mathrm{I} \mathrm{m}^{-2}\right)$ and mean monthly temperature $\left(\mathrm{C}^{\circ}\right)$ data collected from the official meteorological station of the Belgian Royal Meteorological Institute (IRM) in Gembloux-Ernage (near the location of the trials), and (b) mean soil moisture tension $(\mathrm{kPa})$ recorded from soil tensiometer probes (Watermark probes, Irrometer Company, California) at a depth of $25 \mathrm{~cm}$ from the top of the ridge. Data collected for 2012, 2013, and 2014 trials.

tension (Figure 1b) mostly indicated a range corresponding to available water content except for a recorded value over $100 \mathrm{kPa}$ on 22 July. For the 2014 trial, values between 95 and $134 \mathrm{kPa}$ were recorded (Figure 1b) during 2 weeks around mid-June and early July. During this short period, water availability was probably a limiting factor for optimal crop growth and development. Thanks to the precipitation recorded especially at the end of June, the soil moisture tension then decreased up to the range of available water content. For the 2012 and 2013 trials, the period from mid-August to mid-September was clearly dry (Figure 1a) and the corresponding water supply became quite limited. For this analogous period, the soil moisture was not measured for the 2014 trial, but the higher precipitation observed in Figure 1a could suggest that the water supply was not a limiting factor.

\subsection{Effect of $\mathbf{N}$ rate on tuber yield and quality}

A statistical yield response to $\mathrm{N}$ rates was observed particularly between the control treatment $(0 \mathrm{~N})$ and higher tested $\mathrm{N}$ treatments (Figure 2). Differences among the higher $\mathrm{N}$ rates were not significant. For both cultivars, the relationship between yield and $\mathrm{N}$ applied was characterized by an increase of the yield with initial increments of $\mathrm{N}$ rates, reaching a plateau once $\mathrm{N}$ levels 


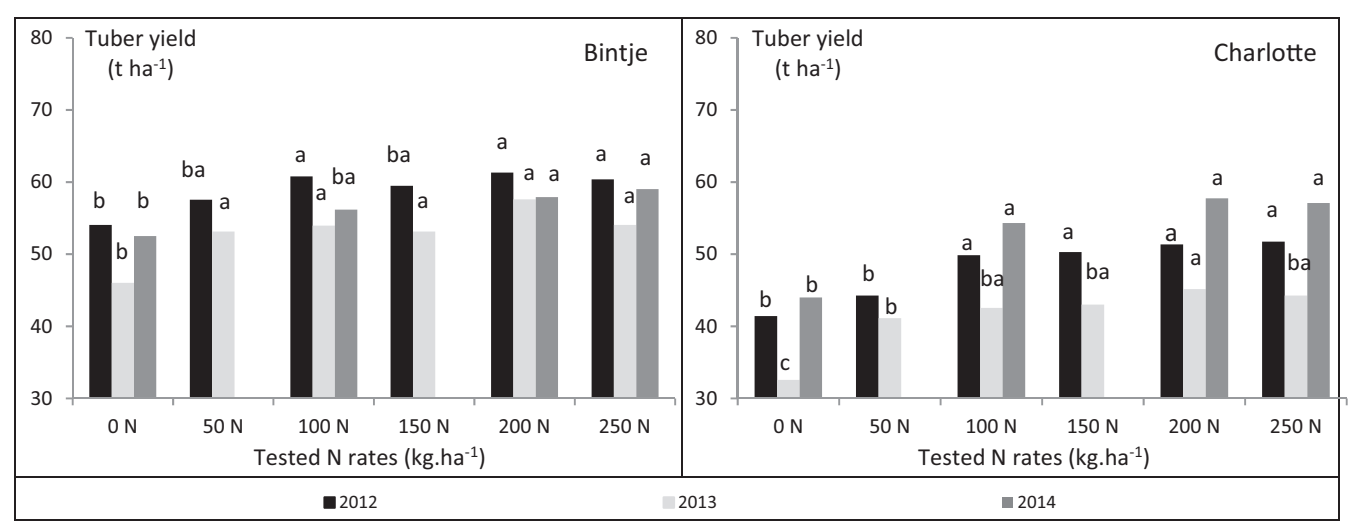

Figure 2. Tuber yield response to increasing $\mathrm{N}$ fertilizer rates in potato crop trials on loam soil in the Gembloux area for two potato cultivars, Bintje and Charlotte (2012, 2013, and 2014 data). Within each year, $\mathrm{N}$ treatments with the same letter are not significantly different at 0.05 level (Student-Newman-Keuls method).

Table 5. The effect of $\mathrm{N}$ fertilizer rates on nitrate content $\left(\mathrm{mg} \mathrm{kg}^{-1}\right.$ fresh weight, $\mathrm{FW}$ ) and dry matter of tubers (\%).

\begin{tabular}{|c|c|c|c|c|c|c|c|}
\hline & \multirow[b]{2}{*}{$\mathrm{N}$ rates } & \multicolumn{3}{|c|}{ Nitrate content $\left(\mathrm{mg} \mathrm{kg}^{-1} \mathrm{FW}\right)$} & \multicolumn{3}{|c|}{ Dry matter (\%) } \\
\hline & & 2012 & 2013 & 2014 & 2012 & 2013 & 2014 \\
\hline \multirow[t]{6}{*}{ Bintje } & 0 & $20^{c}$ & $34^{\mathrm{e}}$ & $29^{d}$ & $25^{\mathrm{a}}$ & $22^{\mathrm{a}}$ & $24^{\mathrm{a}}$ \\
\hline & 50 & $31^{c}$ & $53^{\mathrm{d}, \mathrm{e}}$ & & $25^{\mathrm{a}}$ & $22^{\mathrm{a}, \mathrm{b}}$ & \\
\hline & 100 & $57^{b}$ & $86^{c, d}$ & $49^{c}$ & $24^{\mathrm{b}}$ & $21^{a, b, c}$ & $23^{b}$ \\
\hline & 150 & $64^{\mathrm{b}}$ & $117^{\mathrm{c}, \mathrm{d}}$ & & $24^{\mathrm{b}}$ & $21^{\mathrm{b}, \mathrm{c}}$ & \\
\hline & 200 & $92^{\mathrm{a}}$ & $133^{\mathrm{b}}$ & $92^{\mathrm{b}}$ & $23^{b}$ & $20^{c}$ & $21^{\mathrm{c}}$ \\
\hline & 250 & $98^{\mathrm{a}}$ & $190^{\mathrm{a}}$ & $106^{\mathrm{a}}$ & $23^{b}$ & $20^{c}$ & $21^{c}$ \\
\hline \multirow[t]{6}{*}{ Charlotte } & 0 & $47^{c}$ & $100^{\mathrm{e}}$ & $85^{\mathrm{c}}$ & $22^{\mathrm{a}}$ & $20^{\mathrm{a}}$ & $20^{b}$ \\
\hline & 50 & $51^{c}$ & $147^{d}$ & & $21^{\mathrm{a}}$ & $20^{a, b}$ & \\
\hline & 100 & $63^{\mathrm{c}, \mathrm{b}}$ & $208^{c}$ & $94^{c}$ & $21^{\mathrm{a}}$ & $19^{\mathrm{b}}$ & $21^{\mathrm{a}}$ \\
\hline & 150 & $75^{\mathrm{b}}$ & $265^{b}$ & & $21^{\mathrm{a}}$ & $19^{b, c}$ & \\
\hline & 200 & $101^{\mathrm{a}}$ & $298^{\mathrm{a}}$ & $165^{\mathrm{b}}$ & $21^{\mathrm{a}}$ & $18^{\mathrm{c}}$ & $20^{\mathrm{b}}$ \\
\hline & 250 & $107^{\mathrm{a}}$ & $307^{a}$ & $228^{\mathrm{a}}$ & $21^{\mathrm{a}}$ & $18^{c}$ & $19^{c}$ \\
\hline
\end{tabular}

Within each year and cultivar, $\mathrm{N}$ treatments with the same letter are not significantly different at 0.05 level (Student-Newman-Keuls method).

increased beyond an optimal level. Similar $\mathrm{N}$ response patterns for potatoes have been reported (Westermann and Kleinkopf 1985, Lewis and Love 1994, Long et al. 2004), although in some cases and for some cultivars yields decline beyond an optimal level rather than reaching a plateau (Westermann et al. 1994, Long et al. 2004).

The nitrate and DM contents are indicators of tuber quality generally influenced by $\mathrm{N}$ fertilizers. The increase in $\mathrm{N}$ fertilizer rates clearly increased tuber nitrate content (statistically significant $\mathrm{N}$ effect) and less obviously decreased the DM content (Table 5).

\subsection{Effect of $\mathbf{N}$ rate on the nitrogen nutrition index (NNI)}

The NNI measured across the sampling dates between 20 and 55 DAE for the three trial years is shown in Figure 3. For Bintje, NNI ranged from 0.70 to 1.28 in 2012, from 0.71 to 1.27 in 2013 and from 0.80 to 1.12 in 2014. For Charlotte, NNI showed the same range of values as Bintje (from 0.80 to 1.31 in 2012, from 0.70 to 1.27 in 2013 and from 0.78 to 1.18 in 2014). In the 2012 trial, for example, the value of NNI was $<1.16$ for 0,50 and $100 \mathrm{~N}$ levels, indicating $\mathrm{N}$ deficiency situations. The NNI was almost equal to 1.16 for the $150 \mathrm{~N}$ level, indicating an optimum $\mathrm{N}$ status and $>1.16$ for 200 and $250 \mathrm{~N}$ levels, showing situations of $\mathrm{N}$ excess. 


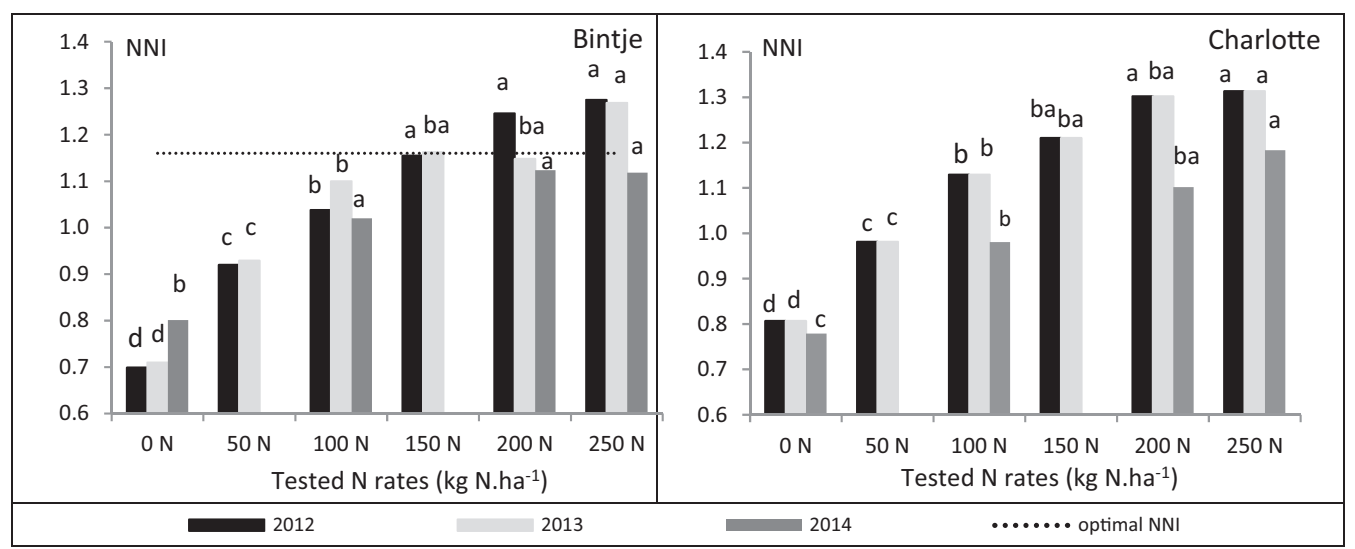

Figure 3. Nitrogen Nutrition Index (NNI) measured across the sampling period (between 20 and $55 \mathrm{DAE}$ ) for increasing $\mathrm{N}$ rates $\left(\mathrm{kg} \mathrm{N} \mathrm{ha}^{-1}\right.$ ) at the site of Gembloux in 2012, 2013, and 2014 for Bintje and Charlotte cultivars. The dotted horizontal line represents a reference NNI of 1.16 obtained from Ben Abdallah et al. (2016b) to maximize tuber yield for the cultivar Bintje. Within each year, $\mathrm{N}$ treatments with the same letter are not significantly different at 0.05 level (Student-Newman-Keuls method).

The NNI calculated for both cultivars showed statistical difference in the $\mathrm{N}$ status, indicating different $\mathrm{N}$ uptake according to the $\mathrm{N}$ fertilizer rate (Figure 3). The evaluation of tuber yield and quality and especially the NNI enabled the determination of the crop's $\mathrm{N}$ response. This is an important aspect confirming that the studied $\mathrm{N}$ treatments led to different $\mathrm{N}$ status; sensitive optical readings would therefore allow similar $\mathrm{N}$ discrimination.

\subsection{Comparison of the studied indices based on their sensitivity, earliness of diagnosis, accuracy, and specificity}

\subsubsection{Sensitivity}

3.4.1.1. Effect of $N$ rate on $N$ indices across the sampling period. Except for SFR-G, the statistical analysis showed that all the studied indices were significantly influenced by applied $\mathrm{N}$ rates (Table 6) among the studied cultivars and across the sampling period (both 2012 and 2013 trials).

Chlorophyll-based indices. The CHL, HNT, and the SFR-R indices decreased with the decrease of $\mathrm{N}$ rates (Table 6). This relationship is in accordance with the reported decrease of LCC under $\mathrm{N}$ deficiency conditions. The CHL index was able to reveal significant differences among the five studied $\mathrm{N}$ rates. The HNT was able to reveal significant differences among all six studied $\mathrm{N}$ rates. The SFR-R index was able to reveal significant differences among the four studied $\mathrm{N}$ rates. Higher average values of $\mathrm{R}$ and $\mathrm{G}$ indices were obtained for the control treatment $(0 \mathrm{~N})$ compared with the other $\mathrm{N}$ rates, whereas the NIR index showed the opposite response to $\mathrm{N}$ rates (Table 6). This opposite dependence on $\mathrm{N}$ rates is explained by the spectral signature that has also been reported by Daughtry et al. (2000) and Goffart et al. (2010). The normalized indices (NormG, NormR and NormNIR) showed similar trends to $\mathrm{N}$ rates compared to their corresponding reflectance indices (respectively G, R, and NIR). The VI increased with $\mathrm{N}$ rates (Table 6). The response of VI, compared to the G, R, and NIR indices, seems to be more sensitive to $\mathrm{N}$, particularly for the GRVI index, which revealed significant differences among the four studied $\mathrm{N}$ rates. Compared to some computed VIs (e.g., OSAVI and RVI), the GRVI index (calculated at 550 and 801 ) responded more to LCC (Daughtry et al. 2000) and then to leaf $\mathrm{N}$ content.

Flavonoid-based indices. The FLV and FLAV indices increased from the N-fertilized treatments to the control treatment (Table 6). This is in agreement with the theory relating increases in LFC to higher $\mathrm{N}$ stress levels. Previous studies have revealed this inverse relationship between 
Table 6. Reading responses of different optical indices (see description in Table 2) to increasing $\mathrm{N}$ fertilizer rates including the sampling period (both 2012 and 2013 trials) and potato cultivars (Bintje and Charlotte) as a whole.

\begin{tabular}{|c|c|c|c|c|c|c|c|c|c|c|}
\hline & & \multicolumn{9}{|c|}{$\mathrm{N}$ effect } \\
\hline & & \multicolumn{2}{|c|}{ ANOVA $^{a}$} & \multicolumn{6}{|c|}{ Multiple-Comparison test ${ }^{\mathrm{b}}$} & \multirow[b]{3}{*}{$\mathrm{RS}^{\mathrm{c}}$} \\
\hline & & \multirow[b]{2}{*}{$F$ value } & \multirow[b]{2}{*}{$\mathrm{Pr}$} & \multicolumn{6}{|c|}{ Tested $\mathrm{N}$ rates $\left(\mathrm{kg} \mathrm{ha}^{-1}\right)$} & \\
\hline & & & & $0 \mathrm{~N}$ & $50 \mathrm{~N}$ & $100 \mathrm{~N}$ & $150 \mathrm{~N}$ & $200 \mathrm{~N}$ & $250 \mathrm{~N}$ & \\
\hline & NBI-R & 263 & $* * *$ & $0.77^{f}$ & $0.92^{\mathrm{e}}$ & $1.10^{d}$ & $1.18^{c}$ & $1.22^{\mathrm{b}}$ & $1.29^{a}$ & 1.68 \\
\hline \multirow{26}{*}{ indices } & NBI-G & 73 & $* * *$ & $2.62^{\mathrm{e}}$ & $3.07^{d}$ & $3.64^{c}$ & $3.82^{c, b}$ & $3.95^{\mathrm{b}}$ & $4.24^{\mathrm{a}}$ & 1.62 \\
\hline & $\mathrm{NBI}$ & 355 & $* * *$ & $24.80^{f}$ & $28.59^{\mathrm{e}}$ & $32.36^{d}$ & $34.88^{C}$ & $36.19^{b}$ & $37.62^{a}$ & 1.52 \\
\hline & HNT/FLV & 389 & $* * *$ & $32.75^{f}$ & $37.41^{\mathrm{e}}$ & $42.34^{d}$ & $44.77^{c}$ & $46.68^{\mathrm{b}}$ & $48.50^{\mathrm{a}}$ & 1.48 \\
\hline & HNT/FLAV & 341 & $* * *$ & $40.72^{f}$ & $46.46^{\mathrm{e}}$ & $52.20^{\mathrm{d}}$ & $55.66^{c}$ & $57.48^{\mathrm{b}}$ & $59.89^{a}$ & 1.47 \\
\hline & $\mathrm{RVI}$ & 32 & $* * *$ & $9.78^{C}$ & $11.82^{\mathrm{b}}$ & $13.20^{\mathrm{a}}$ & $13.30^{\mathrm{a}}$ & $14.23^{\mathrm{a}}$ & $14.23^{\mathrm{a}}$ & 1.46 \\
\hline & FLV & 358 & $* *$ & $1.26^{\mathrm{a}}$ & $1.17^{\mathrm{b}}$ & $1.07^{\mathrm{c}}$ & $1.02^{\mathrm{d}}$ & $0.99^{\mathrm{e}}$ & $0.96^{f}$ & 1.31 \\
\hline & FLAV & 180 & $* * *$ & $1.01^{\mathrm{a}}$ & $0.93^{\mathrm{b}}$ & $0.87^{c}$ & $0.83^{d}$ & $0.81^{d}$ & $0.78^{\mathrm{e}}$ & 1.29 \\
\hline & GRVI & 148 & $* * *$ & $6.08^{\mathrm{e}}$ & $7.02^{d}$ & $7.45^{c}$ & $7.58^{c, b}$ & $7.73^{b, a}$ & $7.79^{\mathrm{a}}$ & 1.28 \\
\hline & NormR & 84 & $* * *$ & $0.10^{\mathrm{a}}$ & $0.08^{\mathrm{b}}$ & $0.08^{c}$ & $0.08^{c}$ & $0.08^{c}$ & $0.08^{c}$ & 1.25 \\
\hline & GDVI & 65 & $* * *$ & $38.75^{c}$ & $43.97^{b}$ & $46.40^{\mathrm{a}}$ & $46.89^{a}$ & $47.88^{\mathrm{a}}$ & $47.68^{\mathrm{a}}$ & 1.25 \\
\hline & DVI & 58 & $* * *$ & $41.05^{c}$ & $46.63^{b}$ & $49.28^{\mathrm{a}}$ & $49.53^{\mathrm{a}}$ & $50.75^{a}$ & $50.47^{a}$ & 1.23 \\
\hline & $\mathrm{R}$ & 72 & $* * *$ & $5.59^{\mathrm{a}}$ & $4.96^{\mathrm{b}}$ & $4.73^{c}$ & $4.76^{\mathrm{c}}$ & $4.68^{c}$ & $4.61^{c}$ & 1.21 \\
\hline & $\mathrm{CHL}$ & 126 & $* * *$ & $29.02^{\mathrm{e}}$ & $30.60^{d}$ & $31.96^{c}$ & $33.29^{b}$ & $33.80^{\mathrm{b}, \mathrm{a}}$ & $34.24^{a}$ & 1.18 \\
\hline & NIR & 49 & $* * *$ & $46.64^{c}$ & $51.55^{\mathrm{b}}$ & $54.00^{\mathrm{a}}$ & $54.34^{\mathrm{a}}$ & $55.27^{\mathrm{a}}$ & $55.02^{\mathrm{a}}$ & 1.18 \\
\hline & NormG & 123 & $* * *$ & $0.13^{\mathrm{a}}$ & $0.12^{\mathrm{b}}$ & $0.12^{c}$ & $0.12^{c}$ & $0.11^{c}$ & $0.11^{\mathrm{C}}$ & 1.18 \\
\hline & HNT & 162 & $* * *$ & $39.09^{f}$ & $40.87^{e}$ & $42.61^{d}$ & $43.41^{c}$ & $44.14^{\mathrm{b}}$ & $44.71^{\mathrm{a}}$ & 1.14 \\
\hline & NDVI & 85 & $* * *$ & $0.77^{\mathrm{c}}$ & $0.81^{\mathrm{b}}$ & $0.82^{\mathrm{a}}$ & $0.82^{\mathrm{a}}$ & $0.83^{\mathrm{a}}$ & $0.83^{\mathrm{a}}$ & 1.08 \\
\hline & SAVI & 85 & $* * *$ & $1.14^{\mathrm{c}}$ & $1.20^{\mathrm{b}}$ & $1.22^{\mathrm{a}}$ & $1.22^{\mathrm{a}}$ & $1.23^{\mathrm{a}}$ & $1.23^{\mathrm{a}}$ & 1.08 \\
\hline & GNDVI & 134 & $* * *$ & $0.70^{\mathrm{d}}$ & $0.73^{c}$ & $0.74^{b}$ & $0.74^{\mathrm{b}, \mathrm{a}}$ & $0.75^{\mathrm{a}}$ & $0.75^{\mathrm{a}}$ & 1.07 \\
\hline & GSAVI & 134 & $* * *$ & $1.04^{\mathrm{d}}$ & $1.09^{c}$ & $1.10^{\mathrm{b}}$ & $1.11^{\mathrm{b}, \mathrm{a}}$ & $1.11^{\mathrm{a}}$ & $1.11^{\mathrm{a}}$ & 1.07 \\
\hline & GOSAVI & 134 & $* * *$ & $0.70^{\mathrm{d}}$ & $0.73^{c}$ & $0.74^{\mathrm{b}}$ & $0.74^{\mathrm{b}, \mathrm{a}}$ & $0.75^{\mathrm{a}}$ & $0.75^{\mathrm{a}}$ & 1.07 \\
\hline & $\mathrm{G}$ & 9 & $* *$ & $7.88^{\mathrm{a}}$ & $7.54^{\mathrm{b}}$ & $7.50^{\mathrm{b}}$ & $7.42^{\mathrm{b}}$ & $7.43^{b}$ & $7.40^{\mathrm{b}}$ & 1.06 \\
\hline & OSAVI & 85 & $* * *$ & $0.77^{c}$ & $0.81^{\mathrm{b}}$ & $0.82^{\mathrm{a}}$ & $0.82^{\mathrm{a}}$ & $0.82^{\mathrm{a}}$ & $0.82^{\mathrm{a}}$ & 1.06 \\
\hline & SFR-R & 62 & $* * *$ & $6.79^{d}$ & $6.93^{c}$ & $7.05^{b}$ & $7.12^{\mathrm{a}}$ & $7.12^{\mathrm{a}}$ & $7.16^{\mathrm{a}}$ & 1.05 \\
\hline & NormNIR & 124 & $* * *$ & $0.77^{c}$ & $0.80^{\mathrm{b}}$ & $0.81^{\mathrm{a}}$ & $0.81^{\mathrm{a}}$ & $0.81^{\mathrm{a}}$ & $0.81^{\mathrm{a}}$ & 1.05 \\
\hline & SFR-G & 1 & ns & $10.91^{\mathrm{a}}$ & $10.50^{\mathrm{a}}$ & $11.37^{\mathrm{a}}$ & $10.90^{\mathrm{a}}$ & $10.86^{\mathrm{a}}$ & $11.40^{\mathrm{a}}$ & 1.04 \\
\hline
\end{tabular}

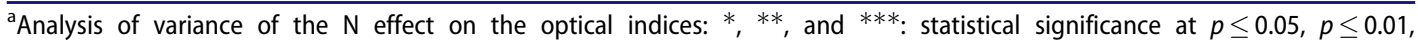
and $p \leq 0.001$, respectively. ns indicates no significance $(p>0.05)$.

${ }^{b}$ Multiple-comparison test (Student-Newman-Keuls method at 0.05 level): values (average of the provided index over the two trial years for both cultivars and all sampling dates) followed by the same letter within each line are not significantly different at 0.05 level.

${ }^{\mathrm{c}}$ Ratio of sensitivity between the index value of $250 \mathrm{~N}$ divided by the index value of $0 \mathrm{~N}$ if the index value of $250 \mathrm{~N}$ is higher than that of $0 \mathrm{~N}$; the reciprocal calculation was made if the index value of $0 \mathrm{~N}$ was higher than that of $250 \mathrm{~N}$.

LFC and increasing $\mathrm{N}$ rates (Cartelat et al. 2005; Tremblay et al. 2007; Zhang et al. 2012). Both of the flavonoid indices were able to reveal significant $\mathrm{N}$ effect. The $\mathrm{N}$ differences were observed among all the studied $\mathrm{N}$ rates case of FLV and among five studied $\mathrm{N}$ rates cases of FLAV.

Chlorophyll- and flavonoid-based indices. The NBI, NBI-G, NBI-R, HNT/FLV, and HNT/ FLAV indices increased from the control treatment $(0 \mathrm{~N})$ up to the treatments with higher $\mathrm{N}$ applications (Table 6). As $\mathrm{N}$ rates increased, LCC increased and LFC decreased, thus explaining the increase in these combined chlorophyll- and flavonoid-based indices. These indices were able to reveal significant $\mathrm{N}$ responses among all the studied $\mathrm{N}$ rates, except for NBI-G (statistical difference between five $\mathrm{N}$ rates).

Taking the computed RS into account, differences in the sensitivity of the studied indices to $\mathrm{N}$ rates can be observed (Table 6). The higher the ratio between high and low $\mathrm{N}$, the higher the sensitivity of the corresponding index. The degree of contrast between low and high $\mathrm{N}$ conditions was expressed by the index in this order: NBI-R $>$ NBI-G $>$ NBI $>$ HNT/FLV $>$ HNT/ FLAV $>$ RVI $>$ FLV $>$ FLAV $>$ GRVI $>$ NormR, GDVI $>$ DVI $>$ R $>$ CHL, NIR, NormG $>$ HNT $>$ NDVI, SAVI $>$ GNDVI, GSAVI, GOSAVI $>$ G, OSAVI $>$ SFR-R, NormNIR $>$ SFR-G. The combined chlorophyll- and flavonoid-based indices (NBI-R, NBI-G, NBI, HNT/FLV, and HNT/ 
FLAV) were ranked as better able to react to a range of contrasting $\mathrm{N}$ conditions, followed by the RVI index and then both the flavonoid indicators (FLV and FLAV). The HNT index was ranked 17 on the list of 27 indices. This result is in accordance with other reports of the superior sensitivity of the combined chlorophyll- and flavonoid-based indices than either of the two indicators used individually (Cartelat et al. 2005; Cerovic et al. 2005; Tremblay et al. 2007; Cerovic et al. 2012).

3.4.1.2. Effect of $N$ rate on $N$ indices per sampling date. NBI-R, HNT/FLV, HNT/FLAV, and FLV revealed a significant $\mathrm{N}$ response for all the sampling dates and for both trials (Table 7). The NBI and FLAV indices were also strongly influenced by $\mathrm{N}$ rates, but with one exception in 2012 the N effect was not significant. This was the case at the beginning of measurement for the NBI (Charlotte at $19 \mathrm{DAE}$ ) and at the end of measurement for the FLAV index (Bintje at 53 DAE).

The HNT index showed sensitive response on all the sampling dates for Bintje in 2013. For Charlotte in 2013 at 14 DAE, the N response of HNT index was not significant. For the 2012 trial, the HNT index showed late $\mathrm{N}$ response (Table 7).

The indices provided by the Cropscan (NormR, NDVI, SAVI, and OSAVI) showed significant $\mathrm{N}$ responses for later measurement dates (Table 7). The GNDVI, GSAVI, and GOSAVI indices showed significant $\mathrm{N}$ responses on all the sampling dates for Bintje 2012, with less sensitive responses for Charlotte in 2012 and late responses for 2013. For R and G indices, the N effect was not very sensitive. This was also the case for the SFR-G index provided by the Multiplex. Out of a total of 26 sampling dates, a nonsignificant $\mathrm{N}$ effect was observed on 18 dates for SFR-G, 19 dates for $G$, and 13 dates for R.

\subsubsection{Earliness of the diagnosis}

3.4.2.1. Effect of $N$ rate on $N$ indices for the first sampling dates. For both trials and cultivars, NBI-R, HNT/FLV, HNT/FLAV, FLV, and FLAV indices were able to reveal significant N response on the first measurement dates (19 and 25 DAE in 2012 and 7-8 and 13 DAE in 2013) (Table 7). NBI-G (except for Charlotte in 2013 at 7 DAE) and NBI (except for Charlotte in 2012 at $19 \mathrm{DAE}$ ) were also able to reveal significant $\mathrm{N}$ responses on early measurement dates. The HNT was able to reveal a significant N effect at an early stage only in the 2013 trial. The NormG, GNDVI, GSAVI, GOSAVI indices showed a significant effect of $\mathrm{N}$ fertilization at early stages for Bintje only in 2012.

Thus, flavonoid indices, whether or not combined with chlorophyll, showed a consistent early response to $\mathrm{N}$ doses, even at 7-8 DAE (for 2013). The UV-induced chlorophyll fluorescence related to the accumulation of polyphenolic content is described as an early spectral signature to detect nitrogen deficiency compared to detections based on changes in reflectance or transmittance linked only to the reduction of the chlorophyll concentration of leaves (Samson et al. 2000; Cadet, 2008). However, the earliness of diagnosis observed at 7-8 DAE should be considered carefully, because at early emergence plants are dependent on the reserves of the seed tubers and there is normally no sudden $\mathrm{N}$ deficiency before 2-3 weeks after emergence.

The indices obtained in 2014 and related to LFC (FLV, FLAV), whether or not combined with LCC (the case of NBI-R, NBI-G, NBI, HNT/FLV, and HNT/FLAV) also match the criteria of sensitivity and earliness of diagnosis (Tables 8 and 9), confirming the previous results. These indices showed significant $\mathrm{N}$ effects across the sampling period (Table 8) and for each sampling date (Table 9). Table 8 supports the previously observed sensitivity of the combined chlorophylland flavonoid-based indices according to the RS. 


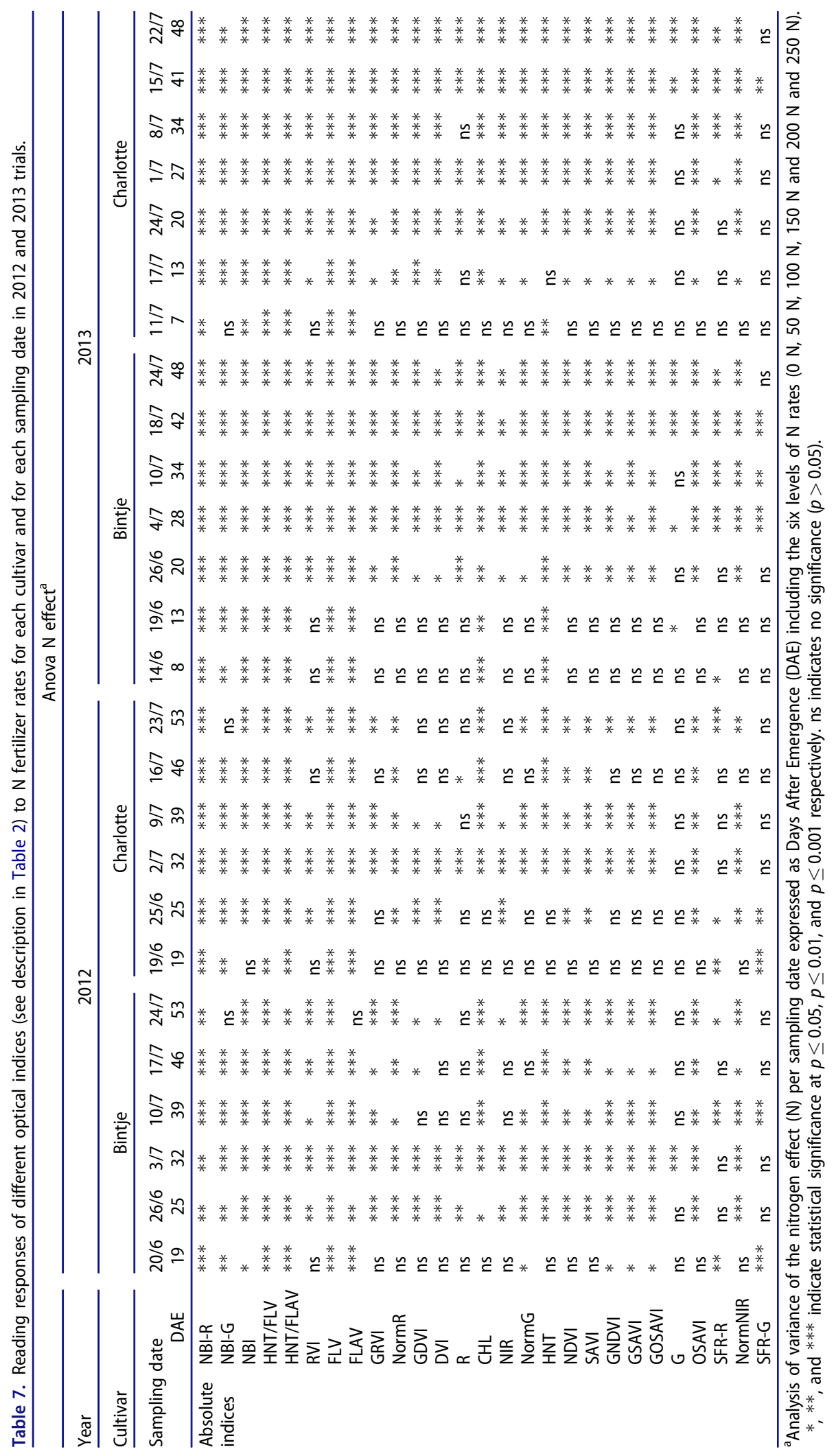


Table 8. Reading responses of flavonoid and/or chlorophyll indices (see description in Table 2) to increasing $\mathrm{N}$ fertilizer rates across the sampling period for the 2014 trial and for both potato cultivars (Bintje and Charlotte).

\begin{tabular}{|c|c|c|c|c|c|c|c|c|}
\hline & & \multicolumn{7}{|c|}{$\mathrm{N}$ effect } \\
\hline & & \multicolumn{2}{|c|}{ ANOVA test ${ }^{\mathrm{a}}$} & \multicolumn{4}{|c|}{ Multiple-comparison test ${ }^{\mathrm{b}}$} & \multirow[b]{3}{*}{$\mathrm{RS}^{\mathrm{c}}$} \\
\hline & & \multirow[b]{2}{*}{$F$ value } & \multirow[b]{2}{*}{$\operatorname{Pr}$} & \multicolumn{4}{|c|}{ Tested $\mathrm{N}$ rates $\left(\mathrm{kg} \mathrm{ha}^{-1}\right)$} & \\
\hline & & & & 0 & 100 & 200 & 250 & \\
\hline Absolute & NBI-R & 134 & $* * *$ & $0.65^{d}$ & $0.89^{c}$ & $1.08^{\mathrm{b}}$ & $1.17^{\mathrm{a}}$ & 1.79 \\
\hline indices & $\mathrm{NBI}-\mathrm{G}$ & 145 & $* * *$ & $2.08^{d}$ & $2.75^{c}$ & $3.33^{\mathrm{b}}$ & $3.57^{\mathrm{a}}$ & 1.72 \\
\hline & $\mathrm{NBI}$ & 161 & $* * *$ & $25.07^{d}$ & $31.58^{c}$ & $35.64^{b}$ & $37.68^{\mathrm{a}}$ & 1.50 \\
\hline & HNT/FLAV & 153 & $* * *$ & $41.78^{d}$ & $51.51^{\mathrm{c}}$ & $58.56^{\mathrm{b}}$ & $61.49^{\mathrm{a}}$ & 1.47 \\
\hline & HNT/FLV & 212 & $* * *$ & $32.96^{\mathrm{d}}$ & $40.34^{\mathrm{c}}$ & $45.22^{b}$ & $46.99^{a}$ & 1.43 \\
\hline & FLAV & 95 & $* * *$ & $1.08^{\mathrm{a}}$ & $0.96^{\mathrm{b}}$ & $0.87^{\mathrm{c}}$ & $0.83^{\mathrm{d}}$ & 1.30 \\
\hline & FLV & 144 & $* * *$ & $1.40^{\mathrm{a}}$ & $1.25^{\mathrm{b}}$ & $1.14^{c}$ & $1.09^{d}$ & 1.29 \\
\hline & $\mathrm{CHL}$ & 133 & $* * *$ & $33.81^{c}$ & $37.59^{b}$ & $39.24^{\mathrm{a}}$ & $39.76^{\mathrm{a}}$ & 1.18 \\
\hline & HNT & 441 & $* * *$ & $43.43^{c}$ & $46.94^{b}$ & $48.84^{\mathrm{a}}$ & $48.95^{\mathrm{a}}$ & 1.13 \\
\hline & SFR-R & 28 & $* * *$ & $7.06^{c}$ & $7.31^{\mathrm{b}}$ & $7.53^{\mathrm{a}}$ & $7.49^{a}$ & 1.06 \\
\hline & SFR-G & 24 & $* * *$ & $9.90^{C}$ & $10.25^{\mathrm{b}}$ & $10.67^{\mathrm{a}}$ & $10.54^{\mathrm{a}}$ & 1.06 \\
\hline
\end{tabular}

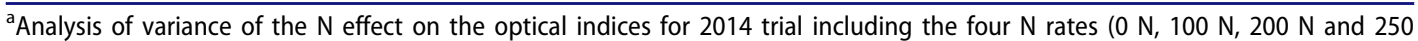
N). $* * *$ : statistical significance at $p \leq 0.001$.

${ }^{\mathrm{b}}$ Multiple-comparison test (Student-Newman-Keuls method at 0.05 level): values (average of the provided index across the 2014 trial for both cultivars and all sampling dates) followed by different letters within each line are significantly different at 0.05 level.

${ }^{c}$ Ratio of sensitivity between the index value of $250 \mathrm{~N}$ divided by the index value of $0 \mathrm{~N}$ if the index value of $250 \mathrm{~N}$ is higher than that of $0 \mathrm{~N}$; the reciprocal calculation was made if the index value of $0 \mathrm{~N}$ was higher than that of $250 \mathrm{~N}$.

Table 9. Reading responses of flavonoids and/or chlorophyll indices (see description in Table 2) to $\mathrm{N}$ fertilizer rates for each cultivar and for each sampling date in the 2014 trial.

\begin{tabular}{|c|c|c|c|c|c|c|c|c|c|c|c|c|c|c|c|}
\hline & \multirow{3}{*}{ 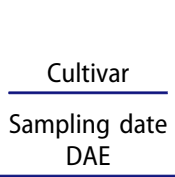 } & \multicolumn{14}{|c|}{ Anova N effect ${ }^{\mathrm{a}}$} \\
\hline & & \multicolumn{7}{|c|}{ Bintje } & \multicolumn{7}{|c|}{ Charlotte } \\
\hline & & $\begin{array}{c}11 / 6 \\
22\end{array}$ & $\begin{array}{c}18 / 6 \\
29\end{array}$ & $\begin{array}{c}26 / 6 \\
37\end{array}$ & $\begin{array}{c}3 / 7 \\
44\end{array}$ & $\begin{array}{c}17 / 7 \\
58\end{array}$ & $\begin{array}{c}24 / 7 \\
65\end{array}$ & $\begin{array}{c}31 / 7 \\
72\end{array}$ & $\begin{array}{c}11 / 6 \\
25\end{array}$ & $\begin{array}{c}16 / 6 \\
30\end{array}$ & $\begin{array}{c}26 / 6 \\
40\end{array}$ & $\begin{array}{c}30 / 6 \\
44\end{array}$ & $\begin{array}{c}17 / 7 \\
61\end{array}$ & $\begin{array}{c}24 / 7 \\
68\end{array}$ & $\begin{array}{c}29 / 7 \\
73\end{array}$ \\
\hline \multirow[t]{11}{*}{ Absolute indices } & $\mathrm{NBI}-\mathrm{R}$ & $* * *$ & $* * *$ & $* * *$ & $* * *$ & $* * *$ & $* * *$ & $* * *$ & $* * *$ & $* * *$ & $* * *$ & $* * *$ & $* * *$ & $* * *$ & $* * *$ \\
\hline & $\mathrm{NBI}-\mathrm{G}$ & $* * *$ & $* * *$ & $* * *$ & $* * *$ & $* * *$ & $* * *$ & $* * *$ & $* *$ & $* *$ & $* * *$ & $* * *$ & $* * *$ & $* * *$ & $* * *$ \\
\hline & $\mathrm{NBI}$ & $* * *$ & $* * *$ & $* * *$ & $* * *$ & $* * *$ & $* * *$ & $* * *$ & $* * *$ & $* * *$ & $* * *$ & $* * *$ & $* * *$ & $* * *$ & $* * *$ \\
\hline & HNT/FLAV & $* * *$ & $* * *$ & $* * *$ & $* * *$ & $* * *$ & $* * *$ & $* * *$ & $* * *$ & $* * *$ & $* * *$ & $* * *$ & $* * *$ & $* * *$ & $* * *$ \\
\hline & HNT/FLV & $* * *$ & $* * *$ & $* * *$ & $* * *$ & $* * *$ & $* * *$ & $* * *$ & * & $* * *$ & $* * *$ & $* * *$ & $* * *$ & $* * *$ & $* * *$ \\
\hline & FLAV & $* * *$ & $* * *$ & $* * *$ & $* * *$ & $* * *$ & $* * *$ & $* * *$ & $* * *$ & $* * *$ & $* * *$ & $* * *$ & $* * *$ & ** & $* * *$ \\
\hline & FLV & $* * *$ & $* * *$ & $* * *$ & $* * *$ & $* * *$ & $* * *$ & $* * *$ & $* * *$ & $* * *$ & $* * *$ & $* * *$ & $* * *$ & $* *$ & $* *$ \\
\hline & $\mathrm{CHL}$ & $* * *$ & $* * *$ & $* * *$ & $* * *$ & $* * *$ & $* * *$ & $* * *$ & $*$ & $* * *$ & $* * *$ & $* * *$ & $* * *$ & $* *$ & $* * *$ \\
\hline & HNT & $* * *$ & $* * *$ & $* * *$ & $* * *$ & $* * *$ & $* * *$ & $* * *$ & $* *$ & $* * *$ & $* * *$ & $* * *$ & $* * *$ & $* * *$ & $* * *$ \\
\hline & SFR-R & ns & ns & $* *$ & $* * *$ & $* *$ & $* * *$ & $* *$ & ns & ns & $*$ & $*$ & $* *$ & $* *$ & $* * *$ \\
\hline & SFR-G & ns & ns & ns & $* * *$ & $*$ & $* * *$ & $* *$ & ns & ns & ns & * & $*$ & * & $* *$ \\
\hline
\end{tabular}

${ }^{a}$ Analysis of variance of the nitrogen effect $(\mathrm{N})$ on optical indices per date including the four $\mathrm{N}$ rates $(0 \mathrm{~N}, 100 \mathrm{~N}, 200 \mathrm{~N}$ and 250 N). DAE: Days After Emergence. $*, * *$, and $* * *$ indicate statistical significance at $p \leq 0.05, p \leq 0.01$, and $p \leq 0.001$, respectively.

\subsubsection{Accuracy}

3.4.3.1. Precision. Table 10 shows the Pearson correlation coefficient between the index and the $\mathrm{N}$ concentration in shoots or in the whole plant biomass. If $r$ is close to -1 , there is a significant negative linear relationship between the optical index and the $\mathrm{N}$ content; if $r$ is close to 1 , there is a strong positive linear relationship. Except for SFR-G and G, the indices showed very highly significant correlations with both the reference methods (either with plant biomass $\mathrm{N}$ content or with shoot biomass $\mathrm{N}$ content) across the period of sampling data as a whole.

The negative significant correlations observed for FLV and FLAV, both across the sampling period and per sampling date (Table 9), confirm the opposite dependence of flavonoid-based indices to $\mathrm{N}$ status (Table 6). The positive significant correlations observed for CHL, NBI, SFR-R, NBI-G, NBI-R, HNT, HNT/FLV, and HNT/FLAV, both across the sampling period and 
per sampling date (Table 10), confirm the relation of these indices (chlorophyll-based indices and chlorophyll- and flavonoid-based indices) to $\mathrm{N}$ status as depicted in Table 6.

For the $\mathrm{R}$ index, the positive correlation with $\mathrm{N}$ content obtained across the sampling period and for the cultivar as a whole is contradictory with the observed correlations per sampling date (negative correlations) (Table 10) and with the described $\mathrm{N}$ relationship depicted in Table 6 (as $\mathrm{N}$ rates increased, $\mathrm{R}$ index decreased from 0 to $250 \mathrm{~N}$ ). Similar contradictory responses were obtained for the other Cropscan indices (NIR index, the normalized indices and the VIs) by comparing the correlations obtained for the sampling period and the cultivar as a whole with those obtained per sampling date (Table 10).

This could be related to different responses of canopy reflectance as the growth stages progress and thus a stableness response of the measurement for different sampling dates. For example, Xue et al. (2004) reported a negative correlation of reflectance at $560 \mathrm{~nm}$ with leaf $\mathrm{N}$ content for each sampling date, but when the data are considered as a whole it seems that a positive relationship existed before the heading stage in rice.

The correlations obtained with $\mathrm{N}$ content when considering the sampling period were higher for NBI-R, NBI, HNT/FLV, HNT/FLAV, FLV, and FLAV indices (coefficients $>0.8$ ) than for the other studied indices. Considering the correlations obtained for each sampling date, these indices (NBI-R, NBI, HNT/FLV, HNT/FLAV, FLV, and FLAV) were ranked in general as the six bestperforming in terms of higher Pearson coefficients. For one date (at $53 \mathrm{DAE}$ ), the FLAV index showed nonsignificant correlation with plant biomass $\mathrm{N}$ content. NBI-G generally showed high correlations (when considering the sampling period as a whole and per sampling date) and thus achieved, like the flavonoid indices, whether or not combined or not with the chlorophyll indices, high performances for precision. The CHL and HNT indices generally showed a statistically significant correlation with $\mathrm{N}$ content per sampling date, but for some early dates (25 DAE for Charlotte in 2012 and 13 DAE in 2013) the correlation was not significant or very small. The precision of the NBI index measured by Dualex and the chlorophyll index measured by SPAD, the other version of HNT chlorophyll-meter, was also assessed by Confalonieri et al. (2015). In this latter study, the NBI demonstrated the highest correlation (per shoots or plant biomass $\mathrm{N}$ content) to the chlorophyll-meter, as was also the case in our study.

For Cropscan indices the obtained correlations with $\mathrm{N}$ content were not always statistically significant and varied with the growth stage (Table 10); thus the precision of Cropscan measurement is less satisfactory than that achieved by flavonoid indices, whether or combined with chlorophyll indices.

3.4.3.2. Repeatability. Repeatability was assessed in this study by the coefficient of variation of the indices calculated between the four repetitions (Table 11). Coefficients of variation $<15 \%$ indicate good repeatability (Pryseley et al. 2010). With the exception of some Multiplex indices (SFR-G and NBI-G) on the last measurement date in 2012 and some Cropscan indices at 46 DAE, the coefficients of variation indicated an acceptable range of repeatability between repetitions. Confalonieri et al. (2015) found that the chlorophyll index (SPAD index measured by chlorophyll-meter) demonstrated higher repeatability than the chlorophyll- and flavonoid-based index (NBI). In this latter study, repeatability was calculated as a function of the standard deviation of repeatability ( $\mathrm{Sr}$ ) and was assessed by performing repeated optical measurements under the same conditions by the same operator.

\subsubsection{Specificity}

The specificity of the indices was studied among four factors: N, cultivar, experimental year, and measurement date (DAE) (Table 12). Ideally, a good index for the evaluation of CNS will be 


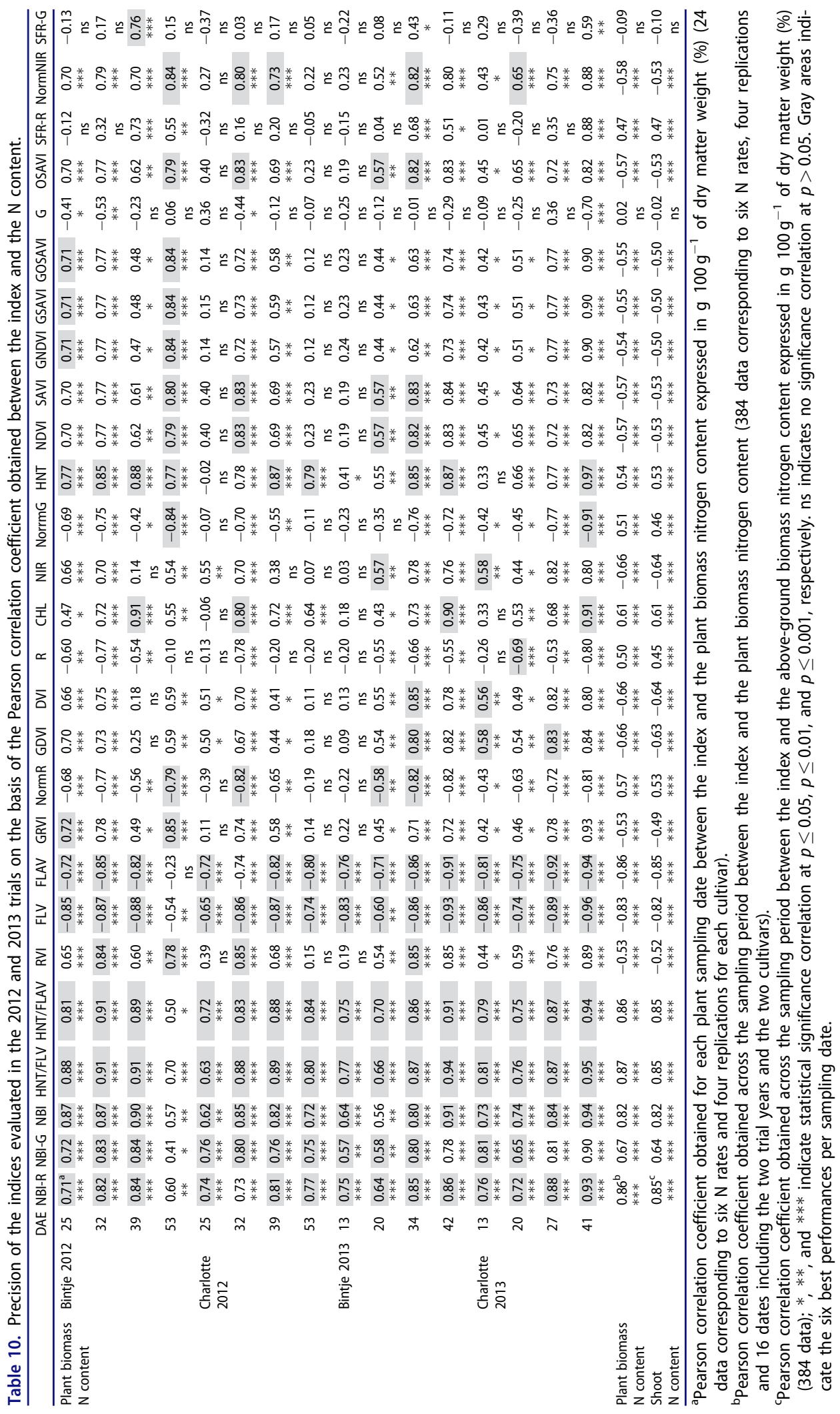




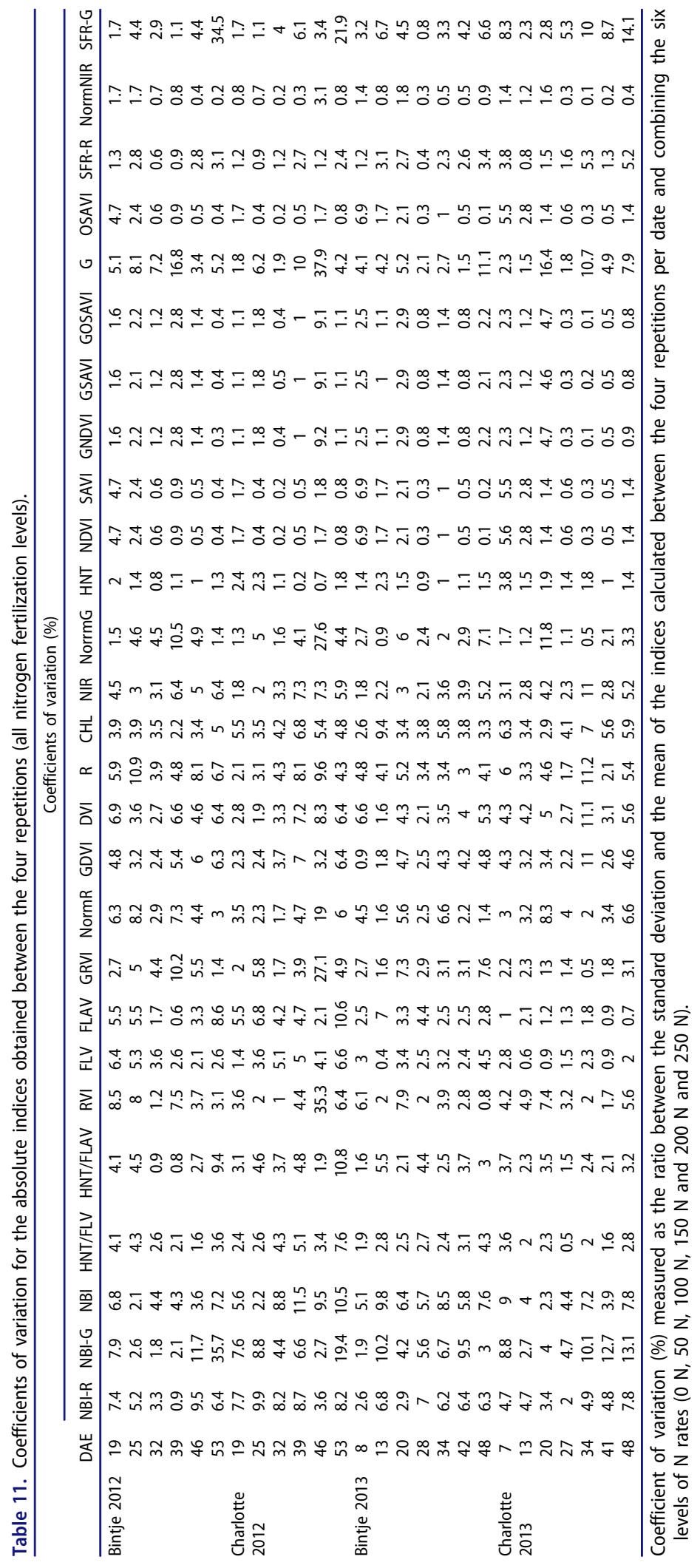




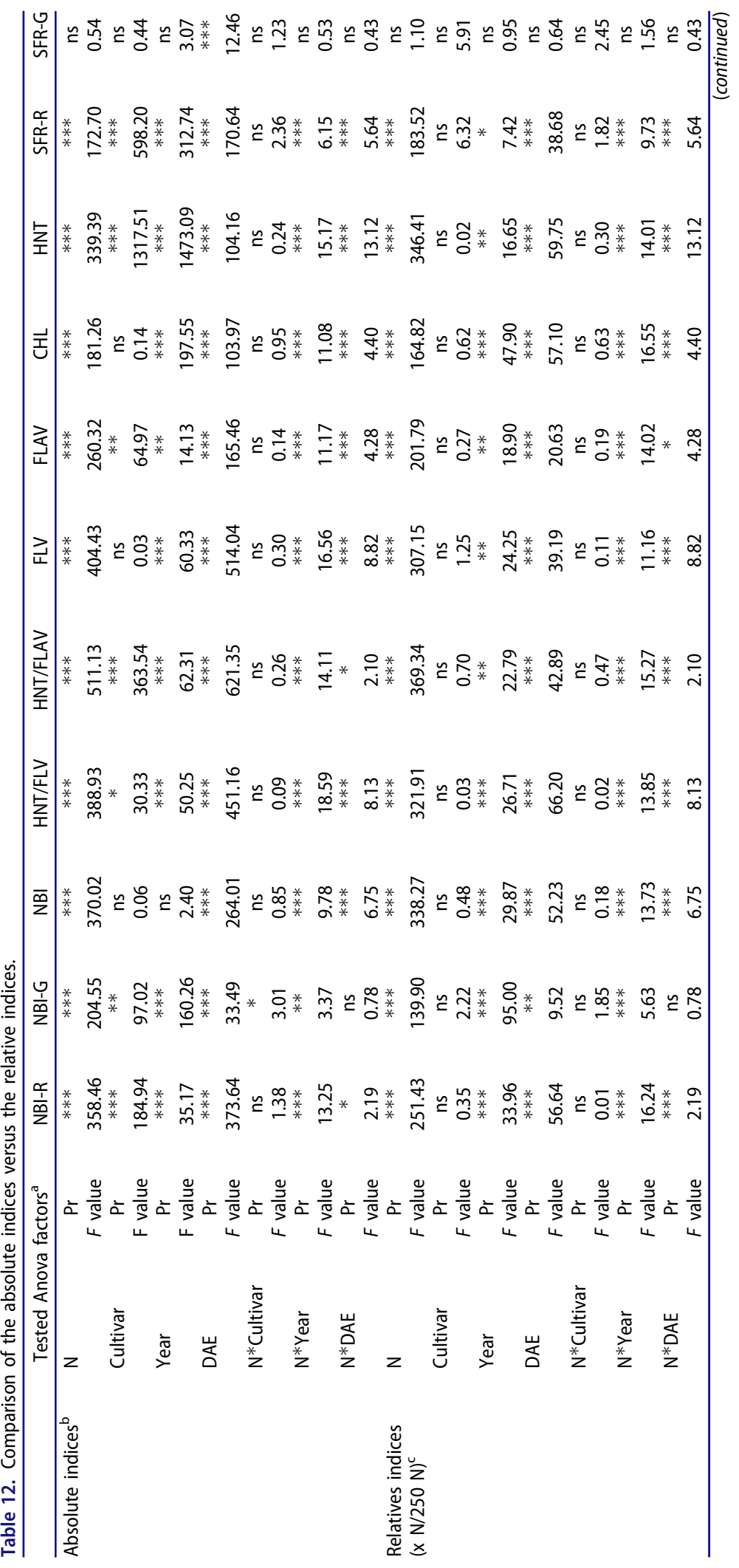




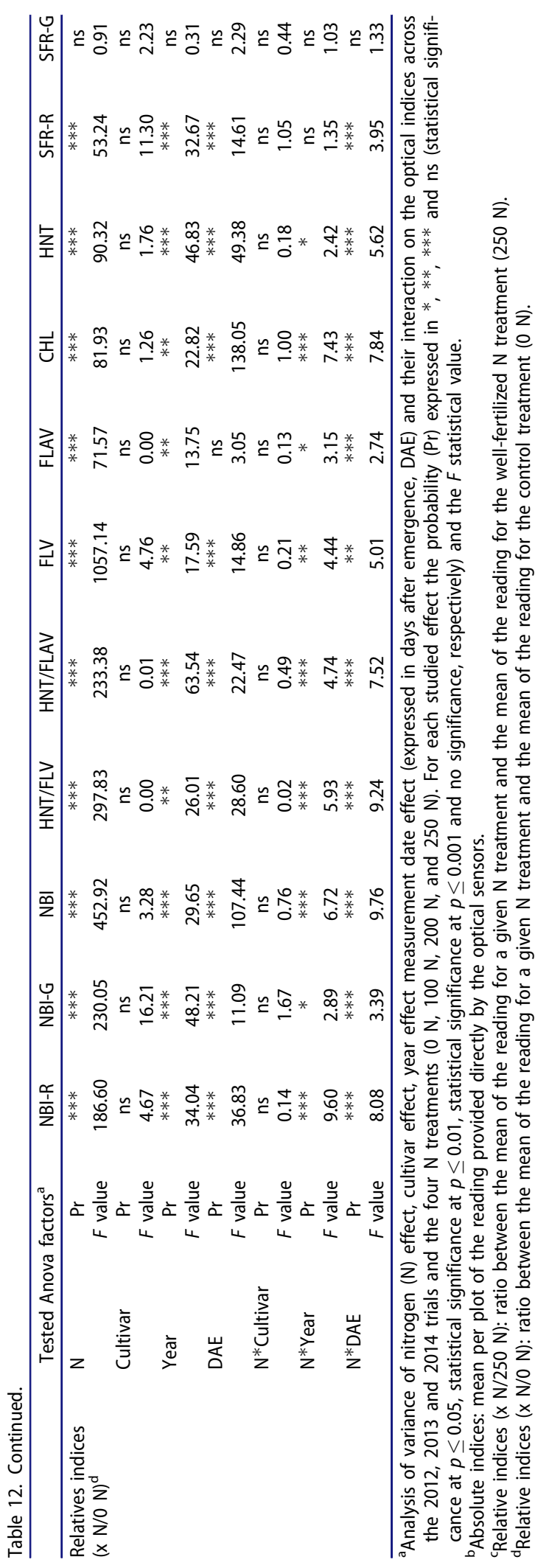


sensitive to $\mathrm{N}$ (significant $\mathrm{N}$ effect) without being influenced by cultivar, year, or DAE (no significant effect).

A significant difference between the two cultivars was observed for most of the absolute indices (Table 12). However, when the relative indices are considered using the well-fertilized reference plot $(250 \mathrm{~N})$ or the control reference plot $(0 \mathrm{~N})$; the cultivar effect indicated no significant difference. The interactions of $\mathrm{N}^{*}$ Cultivar was not significant (except for the absolute NBI index). This is an indication that the $\mathrm{N}$ responses of the indices are consistent for both the studied cultivars (Table 12).

A significant influence of experimental year and DAE was observed in general for both the absolute and the relative indices (Table 12). The interaction effects of $\mathrm{N}^{*}$ year and $\mathrm{N}{ }^{*} \mathrm{DAE}$ were significant for almost all the absolute and relative indices indicating that the responses of indices varied with year and sampling dates. Except for NBI-G and NBI, the absolute indices showed higher $F$ values associated with the year or the DAE factor than with the $\mathrm{N}$ factor. The relative indices in general (except for the CHL index using the $0 \mathrm{~N}$ plot) showed an opposite tendency, with higher $F$ values associated with the $\mathrm{N}$ factor than with the year or the DAE factor. The $F$ values suggested that the significant year or the DAE effect is predominant for the absolute indices, while the significant $\mathrm{N}$ effect is predominant for the relative indices.

The indices provided by optical sensors (absolute indices) therefore showed low specificity to $\mathrm{N}$ (significant effects of factors other than $\mathrm{N}$ ). This low specificity could be alleviated by the use of relative indices (using 0 or $250 \mathrm{~N}$ as reference $\mathrm{N}$ rates) with predominant significant $\mathrm{N}$ effects, smaller year and DAE effects and no significant cultivar effect. This result is in agreement with the need to use normalization procedures for crop measurements to minimize the influence of factors other than $\mathrm{N}$ fertilization on the performance of the optical readings (Schröder et al. 2000; Samborski et al. 2009; Goffart et al. 2013).

The specificity of other factors was not tested in this study. However, many factors affecting crop growth could influence chlorophyll and flavonoid indices. Samson et al. (2000) stated that S deficiency does not affect UV-induced fluorescence (related to the accumulation of polyphenolics content) and decreases LCC. Water stress affects LCC (Gianquinto et al. 2004), but different results have been reported concerning LFC. Fortier et al. (2010) found an increase in flavonoid concentration in the absence of irrigation. In this latter study, LFC was sensed by a Dualex device using both leaf sides. However, Cartelat et al. (2005) stated that the total polyphenolic content remained unchanged, while only the polyphenolic content on the abaxial side of wheat leaves changed. This is due to a change in the allocation of polyphenolics between the two sides of the leaves.

According to the studied criteria of sensitivity, earliness of diagnosis and accuracy, the flavonoid indicator (i.e., FLV index) whether or not combined with chlorophyll indices (i.e., the NBI-R, HNT/FLV, and HNT/FLAV indices) was able to meet all the requirements successfully. However, the criterion of specificity to $\mathrm{N}$ was not achieved for all the studied indices. This low specificity can be improved by the use of relative values.

\section{Conclusion}

Analysis of indices provided from the in-season plant readings shows that indices based on the estimation of LFC (FLV), measured by fluorescence and whether or not combined with LCC (NBI-R, HNT/FLV, HNT/FLAV) are more promising for evaluating the CNS than indices measured by transmittance and reflectance. Despite the fact that absolute indices show low specificity to $\mathrm{N}$ (due to cultivar, sampling date and year effects on the optical readings), which can be improved by the use of relative values, the identified promising indices were able to match the required criteria successfully. These indices were sensitive to crop $\mathrm{N}$ status. The measurements revealed significant difference among all the tested $\mathrm{N}$ rates across the sampling period, 
showed significant $\mathrm{N}$ response on each sampling date and were able to assess highly contrasting $\mathrm{N}$ conditions according to the computed RS. These indices showed an early $\mathrm{N}$ diagnosis compared to the indices provided by the chlorophyll-meter or the radiometer. The identified indices accurately estimated the CNS, since they were closely related to shoot and plant biomass $\mathrm{N}$ content (good precision) and they indicated an acceptable range of repeatability. The NBI index was also as good predictor for CNS as the equivalent indices identified as promising and based on chlorophyll- and flavonoid-based indicators. However, for a single date the sensitivity criterion was not achieved. The FLAV index (measured by the Multiplex) related to LFC could also be considered a good predictor for CNS with slightly less sensitivity than the FLV index (measured by the Dualex). The FLV and NBI-R indices, measured directly by the fluorimeters, seem more suitable for practical application than HNT/FLV and HNT/FLAV indices, since these combined ratios are derived from measures with two different sensors (chlorophyll-meter and fluorimeter) which will limit their use. Another important consideration when comparing optical sensors is the crop surface area that is measured. Dualex and Multiplex measured a surface of $19-20 \mathrm{~mm}^{2}$ and $50 \mathrm{~cm}^{2}$, respectively. In order to take account of field heterogeneity, it is necessary to consider a more representative surface or to compute sufficient replication and adequate sample selection. The expected embedded versions of the fluorimeters positioned further away from the plant will make this possible.

\section{Acknowledgments}

This study was funded by the regional Walloon Public Service (SPW, DGO3, Namur) in Belgium. We would like to thank the Walloon Agricultural Research Centre and particularly the Crops Production Systems unit for their assistance with field operations, sampling and analysis, and the Food and Feed Quality Unit for providing the analytical measurements of total plant nitrogen concentration. The statistical assistance of Elena Pitchugina and Viviane Planchon is gratefully acknowledged.

\section{References}

Agati, G., L. Foschi, N. Grossi, L. Guglielminetti, Z. G. Cerovic, and M. Volterrani. 2013. Fluorescence-based versus reflectance proximal sensing of nitrogen content in Paspalum vaginatum and Zoysia matrella turfgrasses. European Journal of Agronomy 45:39-51. doi.org/10.1016/j.eja.2012.10.011.

Ben Abdallah, F., W. Philippe, and J. P. Goffart. 2016a. Utilisation de la fluorescence chlorophyllienne pour l'évaluation du statut azoté des cultures (synthèse bibliographique). Biotechnology, agronomy. Society and Environment 20 (1):83-93. http://popups.ulg.be/1780-4507/index.php?id =12627.

Ben Abdallah, F., M. Olivier, J. P. Goffart, and O. Minet. 2016b. Establishing the nitrogen dilution curve for potato cultivar bintje in Belgium. Potato Research 59 (3):241-58. doi:10.1007/s11540-016-9331-y.

Ben Ghozlen, N., Z. G. Cerovic, C. Germain, S. Toutain, and G. Latouche. 2010. Non-destructive optical monitoring of grape maturation by proximal sensing. Sensor 10 (11):10040-68. doi:10.3390/s101110040

Bilger, W., M. Veit, L. Schreiber, and U. Schreiber. 1997. Measurement of leaf epidermal transmittance of UV radiation by chlorophyll fluorescence. Physiologia Plantarum 101 (4):754-63. doi:10.1111/j.1399-3054.1997.tb01060.x

Buschmann, C. 2007. Variability and application of the chlorophyll fluorescence emission ratio red/far-red of leaves. Photosynthesis Research 92 (2):261-71. doi:10.1007/s11120-007-9187-8

Cadet, É. 2008. Détection et discrimination des carences en N, P et K par la fluorescence induite par UV chez le tournesol nain (Helianthus annuus, "Sunspot"). PhD diss., Université du Québec à Trois-Rivières.

Cartelat, A., Z. G. Cerovic, Y. Goulas, S. Meyer, C. Lelarge, J.-L. Prioul, A. Barbottin, M.-H. Jeuffroy, P. Gate, G. Agati, and I. Moya. 2005. Optically assessed contents of leaf polyphenolics and chlorophyll as indicators of nitrogen deficiency in wheat (Triticum aestivum L.). Field Crops Research 91 (1):35-49. doi.org/10.1016/ j.fcr.2004.05.002.

Cerovic, Z. G., G. Masdoumier, N. Ben Ghozlen, and G. Latouche. 2012. A new optical leaf-clip meter for simultaneous non-destructive assessment of leaf chlorophyll and epidermal flavonoid. Physiologia Plantarum 146 (3):251-60. doi:10.1111/j.1399-3054.2012.01639.x

Cerovic, Z. G., A. Cartelat, Y. Goulas, and S. Meyer. 2005. In-the-field assessment of wheat-leaf polyphenolics using the new optical leaf-clip Dualex. In Precision agriculture 05, ed. J. V. Stafford, 243-50. Wageningen: Wageningen Academic Publishers. 
Cerovic, Z. G., N. Ben Ghozlen, C. Milhade, M. Obert, S. Debuisson, and M. Le Moigne. 2015. Non-destructive diagnostic test for nitrogen nutrition of grapevine (Vitis vinifera L.) based on Dualex leaf-clip measurements in the field. Journal of Agricultural and Food Chemistry 63 (14):3669-80. doi:10.1021/acs.jafc.5b00304

Confalonieri, R., L. Paleari, E. Movedi, V. Pagani, F. Orlando, M. Foi, M. Barbieri, M. Pesenti, O. Cairati, M. S. La Sala, et al. 2015. Improving in vivo plant nitrogen content estimates from digital images: trueness and precision of a new approach as compared to other methods and commercial devices. Biosystems Engineering 135:21-30. doi:10.1016/j.biosystemseng.2015.04.013

Daughtry, C. S. T., C. L. Walthall, M. S. Kim, E. B. De Colstoun, and J. E. McMurtrey. 2000. Estimating corn leaf chlorophyll concentration from leaf and canopy reflectance. Remote Sensing of Environment 74 (2):229-39. doi:10.1016/S0034-4257(00)00113-9

Fortier, E., Y. Desjardins, N. Tremblay, C. Bélec, and M. Côté. 2010. Influence of irrigation and nitrogen fertilization on broccoli polyphenolics concentration. Acta Horticulturae 856 (856):55-62. doi:10.17660/ ActaHortic.2010.856.6

Froidmont, E., P. Mayeres, P. Picron, A. Turlot, V. Planchon, and D. Stilmant. 2013. Association between age at first calving, year and season of first calving and milk production in holstein cows. Animal 7 (04):665-72. doi:10.1017/S1751731112001577

Gianquinto, G., J. P. Goffart, M. Olivier, G. Guarda, M. Colauzzi, L. Dalla Costa, G. Delle Vedove, J. Vos, and D. K. L. MacKerron. 2004. The use of hand-held chlorophyll meters as a tool to assess the nitrogen status and to guide nitrogen fertilization of potato crop. Potato Research 47 (1-2):35-80. doi:10.1007/BF02731970

Gitelson, A. A., and M. N. Merzlyak. 1998. Remote sensing of chlorophyll concentration in higher plant leaves. Advances in Space Research 22 (5):689-92. doi:10.1016/S0273-1177(97)01133-2

Goffart, J. P., M. Olivier, and M. Frankinet. 2008. Potato crop nitrogen status assessment to improve N fertilization management and efficiency: Past-present-future. Potato Research 51 (3-4):355-83. doi:10.1007/s11540-008-9118-x

Goffart, J. P., L. Van Den Wyngaert, D. Buffet, A. Leonard, and P. Defourny. 2010. SPOT 5 multispectral data potentialities to monitor potato crop nitrogen status at specified field scale. Abstract paper presented at 10th International Conference on Precision Agriculture. Denver. Colorado. USA. July 18-21. 2010.

Goffart, J. P., M. Abras, and F. Ben Abdallah. 2013. Gestion de la fertilisation azotée des cultures de plein champ. Perspectives d'amélioration de l'efficience d'utilisation de l'azote sur base du suivi du statut azoté de la biomasse aérienne. Biotechnology, agronomy. Society and Environment 17 (1):221-30. http://popups.ulg.ac.be/1780-4507/ index.php?id $=9703$.

Goulas, Y., Z. G. Cerovic, A. Cartelat, and I. Moya. 2004. Dualex: a new instrument for field measurements of epidermal UV-absorbance by chlorophyll fluorescence. Applied Optics 43 (23):4488-96. doi:10.1364/AO.43.004488

Guiot, J., J. P. Goffart, and J. P. Destain. 1993. Le dosage des nitrates dans le sol. Bulletin Des Recherches Agronomiques De Gembloux 27 (1):61-74.

Lewis, R. J., and S. L. Love. 1994. Potato genotypes differ in petiole nitrate-nitrogen concentrations overtime. HortScience 29:175-9.

Long, C. M., S. S. Snapp, D. S. Douches, and R. W. Chase. 2004. Tuber yield, storability, and quality of Michigan cultivars in response to nitrogen management and seedpiece spacing. American Journal of Potato Research 81 (5):347-57. doi:10.1007/BF02870181

Meyer, S., Z. G. Cerovic, Y. Goulas, P. Montpied, S. Demotes-Mainard, L. P. R. Bidel, I. Moya, and E. Dreyer. 2006. Relationships between optically assessed polyphenols and chlorophyll contents, and leaf mass per area ratio in woody plants: a signature of the carbon-nitrogen balance within leaves?. Plant, Cell and Environment 29 (7):1338-48. doi:10.1111/j.1365-3040.2006.01514.x

Mittelstraß, K., D. Treutter, M. Pleßl, W. Heller, E. F. Elstner, and I. Heiser. 2006. Modification of primary and secondary metabolism of potato plants by nitrogen application differentially affects resistance to Phytophthora infestans and Alternaria solani. Plant Biology 8:653-661.

Peng, S., F. V. García, R. C. Laza, and K. G. Cassman. 1993. Adjustment for specific leaf weight improves chlorophyll meter's estimate of rice leaf nitrogen concentration. Agronomy Journal 85 (5):987-90. doi:10.2134/ agronj1993.00021962008500050005x

Pryseley, A., K. Mintiens, K. Knapen, Y. Van der Stede, and G. Molenberghs. 2010. Estimating precision, repeatability, and reproducibility from gaussian and non-Gaussian Data: a mixed models approach. Journal of Applied Statistics 37 (10):1729-47. doi:10.1080/02664760903150706

Samborski, S. M., N. Tremblay, and E. Fallon. 2009. Strategies to make use of plant sensors-based diagnostic information for nitrogen recommendations. Agronomy Journal 101 (4):800-16. doi:10.2134/agronj2008.0162Rx

Samson, G., N. Tremblay, A. E. Dudelzak, S. M. Babichenko, L. Dextraze, and J. Wollring. 2000. Nutrient stress of corn plants: early detection and discrimination using a compact multiwavelength fluorescent lidar. In Proceedings of the 20th EARSeL Symposium, Dresden, Germany (pp. 214-223).

Shenk, J., and M. Westerhaus. 1993. Monograph: Analysis of agriculture and food products by Near Infrared Reflectance Spectroscopy. Infrasoft International. Port Matilda. PA-USA. 103 p. 
Schröder, J. J., J. J. Neeteson, O. Oenema, and P. C. Struik. 2000. Does the crop or the soil indicate how to save nitrogen in maize production? Reviewing the state of the art. Field Crops Research 66 (2):151-64. doi:10.1016/ S0378-4290(00)00072-1

Stewart, A. J., W. Chapman, G. I. Jenkins, I. Graham, T. Martin, and A. Crozier. 2001. The effect of nitrogen and phosphorus deficiency on flavonol accumulation in plant tissues. Plant, Cell and Environment 24 (11):1189-97. doi:10.1046/j.1365-3040.2001.00768.x

Tremblay, N., C. Bélec, S. Jenni, E. Fortier, and R. Mellgren. 2009. The Dualex-a new tool to determine nitrogen sufficiency in broccoli. Acta Horticulturae 824 (824):121-31. doi:10.17660/ActaHortic.2009.824.13

Tremblay, N., Z. Wang, and C. Belec. 2007. Evaluation of the Dualex for the assessment of corn nitrogen status. Journal of Plant Nutrition 30 (9):1355-69. doi:10.1080/01904160701555689

Tremblay, N., Z. Wang, and Z. G. Cerovic. 2012. Sensing crop nitrogen status with fluorescence indicators. A review. Agronomy for Sustainable Development 32 (2):451-64. doi:10.1007/s13593-011-0041-1

Vos, J., and M. Bom. 1993. Hand-held chlorophyll meter: a promising tool to assess the nitrogen status of potato foliage. Potato Research 36 (4):301-8. doi:10.1007/BF02361796

Westermann, D. T., and G. E. Kleinkopf. 1985. Nitrogen requirements of potatoes. Agronomy Journal 77 (4):616-21.

Westermann, D. T., T. A. Tindall, D. W. James, and R. L. Hurst. 1994. Nitrogen and potassium fertilization of potatoes: yield and specific gravity. American Journal of Potato Research 71 (7):417-31. doi:10.1007/BF02849097

Xue, L., W. Cao, W. Luo, T. Dai, and Y. Zhu. 2004. Monitoring leaf nitrogen status in rice with canopy spectral reflectance. Agronomy Journal 96 (1):135-42. doi:10.2134/agronj2004.1350

Zhang, Y., N. Tremblay, and J. Zhu. 2012. A first comparison of multiplex ${ }^{\circledR}$ for the assessment of corn nitrogen status. Journal of food, Agriculture and Environment 10 (1):1008-16. 